This item was submitted to Loughborough's Research Repository by the author.

Items in Figshare are protected by copyright, with all rights reserved, unless otherwise indicated.

\title{
On the transient three dimensional tribodynamics of internal combustion engine top compression ring
}

\section{PLEASE CITE THE PUBLISHED VERSION}

http://dx.doi.org/doi:10.1115/1.4035282

\section{PUBLISHER}

(C) American Society of Mechanical Engineers (ASME)

\section{VERSION}

AM (Accepted Manuscript)

\section{PUBLISHER STATEMENT}

This work is made available according to the conditions of the Creative Commons Attribution-NonCommercialNoDerivatives 4.0 International (CC BY-NC-ND 4.0) licence. Full details of this licence are available at: https://creativecommons.org/licenses/by-nc-nd/4.0/

\section{LICENCE}

CC BY-NC-ND 4.0

\section{REPOSITORY RECORD}

Baker, Christopher E., Stephanos Theodossiades, Ramin Rahmani, Homer Rahnejat, and Brian Fitzsimons. 2019. "On the Transient Three Dimensional Tribodynamics of Internal Combustion Engine Top Compression Ring”. figshare. https://hdl.handle.net/2134/23335. 


\title{
On the transient three dimensional tribodynamics of internal combustion engine top compression ring
}

\author{
C. Baker ${ }^{*}$, S. Theodossiades ${ }^{* 1}$, R. Rahmani ${ }^{*}$, H. Rahnejat ${ }^{*}$ and B. Fitzsimons ${ }^{* *}$ \\ "Wolfson School of Mechanical \& Manufacturing Engineering, Loughborough University, \\ Loughborough, UK \\ ${ }^{* *}$ Aston Martin Lagonda, Gaydon, Warwickshire, UK \\ christopher_baker@outlook.com, R.Rahmani@lboro.ac.uk, H.Rahnejat@lboro.ac.uk, \\ Brian.Fitzsimons@astonmartin.com \\ ${ }^{1}$ Corresponding Author (S.Theodossiades@lboro.ac.uk, Tel: + 44 (0) 1509227664 Fax: + 44 (0)
} 1509 227648)

\section{Abstract}

There are increasing pressures upon the automotive industry to reduce harmful emissions as well as meeting the key objective of enhanced fuel efficiency, whilst improving or retaining the engine output power. The losses in an internal combustion engine can be divided into thermal and parasitic as well as due to gas leakage because of untoward compression ring motions. Frictional losses are particularly of concern at low engine speeds, assuming a greater share of the overall losses. Piston-cylinder system accounts for nearly half of all the frictional losses. Loss of sealing functionality of the ring pack can also contribute significantly to power losses as well as exacerbating harmful emissions. The dynamics of compression ring is inexorably linked to its tribological performance, a link which has not been made in many reported analyses. A fundamental understanding of the interplay between the top compression ring three-dimensional elastodynamic behaviour, its sealing function and contribution to the overall frictional losses is long overdue. This paper provides a comprehensive integrated transient elasto-tribodynamic analysis of the compression ring to cylinder liner and its retaining piston groove lands' conjunctions, an 
approach not hitherto reported in the literature. The methodology presented aims to aid the piston ring design evaluation processes. Realistic engine running conditions are used which constitute international drive cycle testing conditions.

\section{Keywords}

Internal combustion engines, piston ring, ring dynamics, tribodynamics, friction, power loss

\section{Nomenclature}

$A-$ Cross-sectional area of the ring

$F_{5 / 2}-$ Greenwood \& Tripp statistical

$A_{a}-$ Asperity contact area function

$A_{c}-$ Nominal contact area of the ring's

$f$-Frequency

contact face-width

$g$ - Ring end gap

$A_{n 1}-A_{n 6}-$ Modal function constants

$h-$ Film thickness

$b$ - Ring contact face-width

$h_{0}-$ Minimum film thickness

$C_{n 1}, C_{n 2}-$ Time response constants

$I_{x}$ - Second moment of area of the ring

$C_{z}$ - Twisting stiffness cross section

$d$ - Ring thickness

$i, j$-Mode number (orthogonality condition)

$d_{n}, e_{n}-$ Modal function constants

$k$-Stiffness parameter

$E-$ Young's modulus of elasticity

$E^{\prime}$ - Composite Young's modulus of elasticity

$F_{e}-$ Ring tension

$m$ - Ring mass per unit length

$p$-Pressure

$p_{a t m^{-}}$Atmospheric pressure

$F_{g}$ - Applied gas force

$p_{e}$ - Elastic pressure due to ring tension

$F_{\text {groove }}-$ Piston groove friction

$p_{g}$ - Gas pressure

$F_{R}-$ Net (residual) radial force

$p_{l}$ - Top ring's leading edge pressure

$F_{T}-$ Tangential shear force

$p_{t}$ - Top ring's trailing edge pressure 
$p_{g v^{-}}$Pressure in ring-groove land

conjunction

$P_{12}$ - Pressure difference between the top and bottom of the ring

$Q_{n}$ - General forcing function

$r$-Crank-pin radius

$R$ - Ring nominal crown radius

$R_{B}-$ Cylinder bore radius

$s-$ Ring axial profile

$t$-Time

$U$-Speed of entraining motion

$V$ - Tangential modal response

$v$-Tangential displacement

W-Radial modal response

$W_{a}-$ Asperity load

$W_{h}-$ Lubricant reaction

$w$-Radial displacement

$x$ - Direction of entraining motion (axial direction of piston)

$y$-Circumferential degree of freedom (direction of groove land)

\section{Greek symbols}

$\alpha$ - Incomplete ring subtended angle

$\alpha_{0}$ - Atmospheric viscosity-pressure coefficient

$\beta_{0}$-Atmospheric viscosity-temperature coefficient
B - Angle of twist

$\Delta$ - Eigenvalue parameter

$\zeta$ - Asperity distribution per unit area

$\eta$ - Lubricant dynamic viscosity

$\eta_{0}$ - Atmospheric dynamic viscosity

$\theta$ - Temperature

$\theta_{0}$-Ambient temperature

$\kappa$ - Average asperity tip radius of curvature

$\lambda_{n}$ - Frequency parameter

$\lambda_{s}$ - Stribeck oil film parameter

$\mu_{n}-$ Modal function constant

$\xi_{n}$ - Time response of ring deflection

$\rho$ - Lubricant density

$\sigma_{n 1-3}-$ Roots of the eigenvalue problem

$\sigma$-Composite roughness of the counterfaces

$\varsigma$-Coefficient of boundary shear strength

$\tau-$ Viscous shear stress

$\tau_{0}-$ Eyring shear stress of the lubricant

$\phi$-Crank angle

$\varphi$ - Direction along the ring periphery

$\omega_{f}-$ Excitation frequency

$\omega_{n}-$ Natural frequency

Subscripts/Abbreviations

$B D C$ - Bottom Dead Centre 
c-Composite

$n$ - Mode shape index

FDM - Finite Difference Method
FEA - Finite Element Analysis

IC - Internal Combustion Engine

TDC - Top Dead Centre

\section{Introduction}

The drive for fuel efficiency and reduced emissions calls for the reduction of IC (internal combustion) engine losses, comprising thermal and parasitic (pumping, friction). Thermal losses are the main contributors, but at low engine speeds the frictional losses are also quite significant. Low engine speeds correspond to the stop-start driving patterns seen in city driving, which progressively account for an ever greater proportion of typical vehicle use. The parasitic losses accounts for $15-20 \%$ of all the engine losses, with the piston-cylinder system having a $40-50 \%$ share. The piston top compression ring is designed to closely conform to the bore surface to seal the combustion chamber. Effective sealing in this conjunction has the adverse effect of increased frictional losses, which is quite disproportionate to its size. On the other hand, any degree of non-conformity would result in a plethora of problems, including power loss, blow-by, increased emissions, oil loss and lubricant degradation, to name but a few. Therefore, study of frictional losses from ringbore conjunction is a complex multi-variate problem which should include combined solution of transient lubrication and instantaneous three dimensional ring dynamics.

With respect to the dynamic behaviour, the ring is subject to a complex combination of motions, constrained firstly by the limits set by its retaining piston grooves, and secondly by the liner surface. Smedley [1] describes the pioneering work from the mid-1800s, regarding ring dynamics in steam engines. Using the steam pressure to improve the ring's sealing force 
through its flexibility, thus improving ring-bore conformability. This was also noted by Priest and Taylor [2]. Furuhama et al [3-5] carried out combined numerical and experimental investigations into tribology of the compression ring. These studies showed that ring flutter occurs where the sealing capability of the compression ring is compromised, causing it to vibrate and undergo extreme deformation behaviour.

Tian et al [6] presented a study of ring dynamics and gas flow in a three-ring pack. It was found that static twist (the relative angle between the ring and its retaining groove) influences the ring-groove contact characteristics, stability and blow-by (flow of gasses from the combustion chamber into the crankcase). It was assumed that a layer of lubricant would be present on both the retaining grooves' surfaces (in- and out- of the ring plane), allowing for a simplified Reynolds equation to be used to calculate the lubricant reactions between the ring and the groove lands. Tian [7] described how both diesel and gasoline engines are affected by the motion of the ring, notably ring flutter and collapse. Furthermore, Fox et al [8] stated that in recent years there has been an attempt to reduce lubricant availability to the compression ring - cylinder liner conjunction in order to reduce engine emissions. As a result, the contribution of the top ring to ring pack friction has increased from approximately $13 \%$ in the 1980 s to around $27 \%$ today [9]. A contribution between $13-40 \%$ is generally noted, depending on the engine type and running conditions [9]. Clearly, reduction in frictional losses is one of the key objectives. In fact, a $10 \%$ reduction in mechanical losses reduces the fuel consumption by approximately $1.5 \%$ [2].

The deformation of the bore and ring can originate from thermal and mechanical loading, cylinder head bolt tightening and abrasion [10-12]. In practice, the bore is not a right circular cylinder, which affects the ring-bore conjunctional friction and gas flow [13]. This lack of 
conformity would be further exaggerated by complex ring dynamics, leading to blow-by which would reduce engine power, sometimes even outweighing any frictional losses from the same conjunction. Poor ring-bore conformability may also cause increased ingression of oil flow into the chamber, adding to the emissions [14].

With regard to the reported analyses, ring conformability is considered as the combined effect of ring elastic tension and gas pressure loading on the inner rim of ring, both striving to conform the ring to the cylinder surface [15]. Mishra et al [16] analysed the ring-bore conjunction, including ring in-plane conformability in an isothermal analysis. Mixed and boundary lubrication conditions were assumed at the TDC and BDC, showing reasonably good agreement with the experimental friction measurements of Furuhama and Sasaki [17] under engine motored condition. The deviations between the numerical predictions of friction [16] and the measurements [17] were seen to be due to ring dynamics as well as generated heat in the contact, not included in the analysis. The effect of shear and compressive heating of the lubricant in the ring-bore conjunction under engine motored (not fired condition) was found to be marginal, when compared to an isothermal analysis by Baker et al [18]. The same, of course, is not true of engine fired condition, where there is still a dearth of comparative studies, owing to measurement of friction from the compression conjunction in isolation from the whole piston-cylinder system under fired condition. Therefore, at least under motored condition, with sufficient chamber pressure complex ring dynamic behaviour may account for the noted differences between the predictions [16] and the experimental measurements [17].

Dowson et al [19] examined the influence of ring twist, suggesting that the contact between the ring and the groove land is a critical factor inducing ring flutter. Their study assumed 
that the axial ring motion closely followed that of the piston, once contact between the two bodies was established. Tian et al [20] considered both the ring twist and a gas flow model. A one dimensional, analytical solution of Reynolds equation was used to calculate the pressure profile along the piston groove. However, the ring dynamics employed did not include any transient elastic response of the compression ring. Tian [7, 20] has shown the effect of ring flutter on gas flow and oil transport. A formula was presented, showing the critical parameters which would avoid the ring radial collapse. Kurbet and Kumar [21] developed a three dimensional finite element (FE) model of the piston and compression ring, including ring twist and piston secondary tilting motion. They concluded that piston tilt significantly affects the dynamics of the compression ring. Recently, Baelden and Tian [22] developed a curved beam finite element model for piston compression ring, considering its structural deformation and contact with the cylinder liner. They showed that the traditional conformability analysis $[15,16,23]$ does not take into account the complex behaviour of the ring dynamics.

Baker et al $[24,25]$ included the effect of in-plane (radial) ring dynamics in quasi-static and transient lubrication study of piston compression ring - cylinder liner conjunction. Their results show progressively better conformance of numerical predictions with experimental measurements of lubricant film thickness reported by Takiguchi et al [26]. It is therefore, clear that a combined in-plane and out-of-plane ring dynamic analysis should be considered under transient analysis, which is the main contribution of the current paper. The combined solution of complex three dimensional ring elastodynamics with transient tribological analysis has not hitherto been reported in literature. 


\section{Methodology}

i) Ring dynamics (out-of-plane and in-plane ring motions).

The out-of-plane ring dynamics are studied, making the following assumptions:

- The ring is considered to be a thin structure as its neutral radius is an order of magnitude larger than its thickness.

- Rotary inertia is neglected because of the ring thinness and its relatively low mass as well as lack of any significant rotational speed.

- The neutral axis of the ring is assumed to be inextensible $(d / r \approx 0.0814<0.1)$.

Ojalvo [27] uses Hamilton's Principle to determine that an actual motion yields a stationary integral, $I$ :

$$
\delta I=\int_{t 0}^{t 1}(\bar{T}-\bar{V}) d t=0
$$

where $\bar{T}$ and $\bar{V}$ are the kinetic and potential energies of the system. The sign convention can be seen in figure 1 , with the $z$ axis being tangential to the beam. The potential energy can be defined as [27]:

$$
\bar{V}=\int_{0}^{\alpha}\left[\left\{\frac{M_{x}^{2}}{2 E I_{x}}+\frac{M_{y}^{2}}{2 E I_{y}}+\frac{M_{z}^{2}}{2 C_{z}}\right\}-\{X w+Y u+Z v+\Phi \beta\}\right] R d \theta
$$

where $X, Y$ and $Z$ are forces per unit length along the principal axes. The internal moments are defined as:

$$
\begin{aligned}
& M_{x}=\frac{E I_{x}}{R^{2}}\left(R \beta-\frac{\partial^{2} u}{\partial \varphi^{2}}\right) \\
& M_{y}=\frac{E I_{y}}{R^{2}}\left(\frac{\partial^{2} w}{\partial \varphi^{2}}-\frac{\partial v}{\partial \varphi}\right) \\
& M_{x}=\frac{C_{z}}{R^{2}}\left(R \frac{\partial \beta}{\partial \varphi}-\frac{\partial u}{\partial \varphi}\right)
\end{aligned}
$$


As rotary inertial components are neglected, the kinetic energy of the system becomes:

$$
\bar{T}=\int_{0}^{\alpha}(m / 2)\left[\dot{u}^{2}+\dot{v}^{2}+\dot{w}^{2}\right] R d \theta
$$

The out-of-plane degrees of freedom are the axial displacement, $u$, and the twist angle about the neutral axis, $\beta$, as shown in Figure 1. Equations (3-5) are then substituted into equation (2), with the equation (6) substituted into equation (1). The resulting EulerLagrange equations for the ring out-of-plane motion become [27]:

$$
\begin{aligned}
& \frac{\partial^{4} u}{\partial \varphi^{4}}-R \frac{\partial^{2} \beta}{\partial \varphi^{2}}-k\left(\frac{\partial^{2} u}{\partial \varphi^{2}}-R \frac{\partial^{2} \beta}{\partial \varphi^{2}}\right)=\frac{m R^{4}}{E I_{x}}\left(\frac{\partial^{4} u}{\partial t^{2}}-\frac{Y}{m}\right) \\
& \frac{\partial^{2} u}{\partial \varphi^{2}}-R \beta+k\left(\frac{\partial^{2} u}{\partial \varphi^{2}}+R \frac{\partial^{2} \beta}{\partial \varphi^{2}}\right)=\frac{m R^{4}}{E I_{x}}\left(\frac{\Phi_{F}}{m}\right)
\end{aligned}
$$

where $Y$ and $\Phi_{F}$ denote the forcing and torsional loading. It is noted that there is no in-plane degrees of freedom in equations (7) and (8) since the two problems are treated as uncoupled.

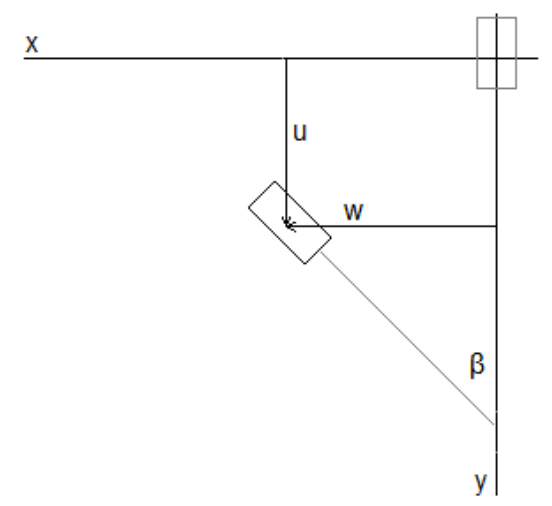

Figure 1: Ring cross-section exhibiting its out-of-plane motion [27]

The torsional loading in this problem is considered as negligible; $\Phi_{F}=0$. Rearranging equation (8) and substituting into equation (7) yields:

$$
\frac{\partial^{4} \beta}{\partial \varphi^{4}}+2 \frac{\partial^{2} \beta}{\partial \varphi^{2}}+\beta=\frac{m R^{4}}{C_{z}}\left(\frac{1+k}{R}\right)\left(\frac{\partial^{2} u}{\partial t^{2}}-\frac{Y}{m}\right)
$$


where $m$ is the ring mass per unit length, $C_{z}$ is its twisting stiffness and $k$ is the stiffness parameter: $\frac{C_{z}}{E I_{x}}$. The out-of-plane dynamic response takes the form of a solution, comprising spatial and temporal functions as:

$$
\begin{gathered}
u(\varphi, t)=\sum_{n=1}^{\infty} U_{n}(\varphi) \xi_{n}(t) \\
\beta(\varphi, t)=\sum_{n=1}^{\infty} \beta_{n}(\varphi) \xi_{n}(t) \\
Y=f(t) \sum_{n=1}^{\infty} Q_{n} U_{n}(\varphi)=f(t) W(\varphi)
\end{gathered}
$$

where $U_{n}(\phi)$ represents the translational mode shapes, $\beta_{n}(\varphi)$; the out-of-plane twist mode and $Q_{n}$, the forcing function. Equations (10) and (11) represent the solution forms for the out-of-plane displacement and twist. Equation (12) shows the form of forcing function, $Y$, which varies with respect to both time and the angular coordinate $\varphi$ around the ring's periphery. Substitution of equations (10)-(12) into equation (9) yields:

$$
\xi_{n}\left(\frac{\partial^{4} \beta_{n}}{\partial \varphi^{4}}+2 \frac{\partial^{2} \beta_{n}}{\partial \varphi^{2}}+\beta_{n}\right)=\frac{m R^{4}}{C_{z}}\left(\frac{1+k}{R}\right)\left(\ddot{\xi}_{n}-\frac{Q_{n}}{m} f(t)\right) u_{n}
$$

Separation of variables in equation (13) and dividing through by $\xi_{n} u_{n}$, yields:

$$
-\lambda_{n}\left(\frac{1+k}{R}\right)=-\omega_{n}^{2}\left(\frac{1+k}{R}\right) \frac{m R^{4}}{C_{z}}
$$

From Equations (13) and (14), the homogeneous and non-homogenous parts of the out-ofplane dynamic response are derived [28]:

$$
\begin{gathered}
\frac{\partial^{4} \beta_{n}}{\partial \varphi^{4}}+2 \frac{\partial^{2} \beta_{n}}{\partial \varphi^{2}}+\beta_{n}=-\lambda_{n}\left(\frac{1+k}{R}\right) u_{n} \\
\ddot{\xi}_{n}+\omega_{n}^{2} \xi_{n}=\frac{Q_{n}}{m} f(t)
\end{gathered}
$$

In the piston ring-cylinder liner conjunction, the out-of-plane force profile comprises:

(i) the reaction force from the piston groove due to piston's motion,

(ii) gas pressure acting on the ring, 
(iii) contact friction generated in the ring-cylinder conjunction

(iv) the ring's inertial response

Thus, the resultant is a time-dependent distributed loading. The dynamic response is a function of the ring's modal response, as well as the influence of the external forcing term:

$$
Q_{n}=\frac{\int_{0}^{\alpha}\left(W(\varphi) u_{n}\right) d \varphi}{\int_{0}^{\alpha} u_{n}^{2} d \varphi}
$$

Equation (17) represents the force profile as it varies spatially (with $\alpha$ being the maximum subtended angle of the ring), whereas $f(t)$ in equation (16) is the time varying component of the force. To derive the characteristic equation of the out-of-plane problem, equation (7) is rearranged and doubly integrated to find an expression for $u_{n}$ as:

$$
u_{n}=\left(\frac{R}{1+k}\right)\left(\iint_{0}^{\alpha} \beta_{n} d \varphi-k \beta_{n}\right)
$$

A solution is assumed for $\beta_{n}$ as:

$$
\beta_{n}=\sum_{K=1}^{3}\left(A_{n K} \sin \sigma_{n K} \varphi+B_{n K} \cos \sigma_{n K} \varphi\right)
$$

Substitution of equations (18) and (19) into equation (15) yields:

$$
\begin{array}{r}
\sum_{K=1}^{3}\left(\sigma_{n K}^{4}-2 \sigma_{n K}^{2}+1\right)\left(A_{n K} \sin \sigma_{n K} \varphi+B_{n K} \cos \sigma_{n K} \varphi\right)= \\
\lambda_{n} \sum_{K=1}^{3}\left(\frac{1}{\sigma_{n K}^{2}}+k\right)\left(A_{n K} \sin \sigma_{n K} \varphi+B_{n K} \cos \sigma_{n K} \varphi\right)
\end{array}
$$

All the terms involving $\varphi$ are linearly independent. Therefore, the characteristic equation can be derived as:

$$
\left(\sigma_{n K}^{6}-2 \sigma_{n K}^{4}+\sigma_{n}^{2}\right)=\lambda_{n}\left(1+k \sigma_{n}^{2}\right)
$$

The cubic equation (22) is formed below, the solutions to which are given in terms of $\lambda_{n}$. The form of the roots for this equation varies according to Burington [29]:

$$
S_{n}^{3}+p S_{n}^{2}+q S_{n}+r=0
$$


Let:

$$
\begin{gathered}
a \equiv\left(3 q-p^{2}\right) / 3 \\
b \equiv\left(2 p^{3}-9 p q+27 r\right) / 27 \\
\Delta \equiv\left(b^{2} / 4\right)+\left(a^{3} / 27\right)
\end{gathered}
$$

Thus, the three roots of the cubic equation (22) depend on $\Delta$ :

a. If $\Delta>0$, there is one real root and two complex conjugates as:

$$
\sigma_{n 1}=s 1, \quad \sigma_{n 2}=\mu+i v, \quad \sigma_{n 3}=\mu-i v
$$

The solution form is as follow:

$$
\begin{gathered}
\beta_{n}=A_{n 1} \sin \sigma_{n 1} \varphi+A_{n 2} \sin \mu \varphi \cosh v \varphi+A_{n 3} \cos \mu \varphi \sinh v \varphi+B_{n 1} \cos \sigma_{n 1} \varphi+ \\
B_{n 2} \cos \mu \varphi \cosh v \varphi+B_{n 3} \sin \mu \varphi \sinh v \varphi
\end{gathered}
$$

b. If $\Delta=0$, then $\sigma_{\mathrm{n} 2}=\sigma_{\mathrm{n} 3}$, yielding:

$\beta_{n}=A_{n 1} \sin \sigma_{n 1} \varphi+\left(A_{n 2}+A_{n 3}\right) \sin \sigma_{n 3} \varphi+B_{n 1} \cos \sigma_{n 1} \varphi+\left(B_{n 2}+B_{n 3}\right) \cos \sigma_{n 3} \varphi(24)$

c. If $\Delta<0$, there are two possibilities:

c.1: if $k \lambda_{n}<1$, there are 3 positive and unequal roots as:

$$
\beta_{n}=A_{n 1} \sin \sigma_{n 1} \varphi+A_{n 2} \sin \sigma_{n 2} \varphi+A_{n 3} \sin \sigma_{n 3} \varphi+B_{n 1} \cos \sigma_{n 1} \varphi+B_{n 2} \cos \sigma_{n 2} \varphi+
$$

c.2: and finally, if $k \lambda_{n}>1$, there is one real and two imaginary roots as:

$$
\beta_{n}=A_{n 1} \sin \sigma_{n 1} \varphi+A_{n 2} \sinh \sigma_{n 2} \varphi+A_{n 3} \sinh \sigma_{n 3} \varphi+B_{n 1} \cos \sigma_{n 1} \varphi+B_{n 2} \cosh \sigma_{n 2} \varphi+
$$

Considering equations (23)-(26), the expression for the out-of-plane modal displacement becomes:

$$
U_{n}=\left(\frac{1}{\sigma^{2}}+k\right) \beta_{n}
$$


Archer [30] stated that the solutions with the form of equation (24) are only valid when the total ring subtended angle is greater than $2 \pi$. Therefore, for the case of a compression ring, equations (23) and (26) are the relevant solution forms. These are substituted into equation (19), which is in turn substituted into the boundary conditions [28]:

$$
\begin{gathered}
M_{x}=\left(R \beta-\frac{\partial^{2} \beta}{\partial \varphi^{2}}\right) \\
M_{Z}=\left(R \frac{\partial \beta}{\partial \varphi}+\frac{\partial u}{\partial \varphi}\right) \\
V=\frac{\partial\left(\frac{\partial^{2} u}{\partial \varphi^{2}}-R \beta\right)}{\partial \varphi}-k\left(\frac{\partial u}{\partial \varphi}+R \frac{\partial \beta}{\partial \varphi}\right)
\end{gathered}
$$

Equations (29)-(30) represent the bending moments and normal force. The boundary conditions are found by equating the same to zero for $\varphi=0$ and $\varphi=\alpha$ in the case of an incomplete ring (unrestrained at both ends). This gives a set of 6 equations, each being a function of constants $A_{n 1-3}$ and $B_{n 1-3}$. Equating the determinant of this $6 \times 6$ matrix to zero and solving for the roots, the natural frequency parameters $\lambda_{n}$ can be obtained.

An FEA model of the ring (built in PATRAN/NASTRAN software) is used to validate the developed ring dynamics methodology. The FEA model contains 1024 nodes, each with 6 degrees of freedom with free boundary conditions assumed at each ring extremity. Table 1 shows a comparison between the natural frequencies predicted by the analytical method and the corresponding results from FEA analysis. Very good agreement is observed. Figure 2 shows examples of the ring mode shapes.

With regard to the in-plane ring dynamic behaviour, a similar approach to that expounded above for the case of the out-of-plane ring dynamics is followed (considering that the two sets of equations of motion are de-coupled for small deflections). The degrees of freedom employed for the in-plane case are the radial and tangential deflections, $w$ and $v[24,25]$, as 
opposed to the out-of-plane deflection and ring twist. Further information on the in-plane ring dynamics can be found in Baker et al [24, 25]. Additionally, whilst a finite element analysis is useful for validating the dynamics of the proposed methodology, the inclusion of a tribological model into the FEA would result in very long computation times. The required processing power for such an approach would be far too high to deliver results in a timely manner, compared with the presented semi-analytical methodology.

Table 1: Out-of-plane natural frequencies of the compression ring

\begin{tabular}{cccc}
\hline Mode Number & $\begin{array}{c}\text { Analytical Method } \\
\text { Natural Frequency }(\mathrm{Hz})\end{array}$ & $\begin{array}{c}\text { FEA model } \\
\text { Natural Frequency }(\mathrm{Hz})\end{array}$ & \% Difference \\
\hline 1 & 92.54 & 93.33 & 0.846 \\
\hline 2 & 254.29 & 256.42 & 0.828 \\
3 & 534.92 & 538.91 & 0.74 \\
4 & 903.02 & 908.57 & 0.611 \\
5 & 1357.72 & 1366.52 & 0.644 \\
6 & 1889.86 & 1901.72 & 0.624 \\
7 & 2506.75 & 2520.66 & 0.552 \\
\hline
\end{tabular}



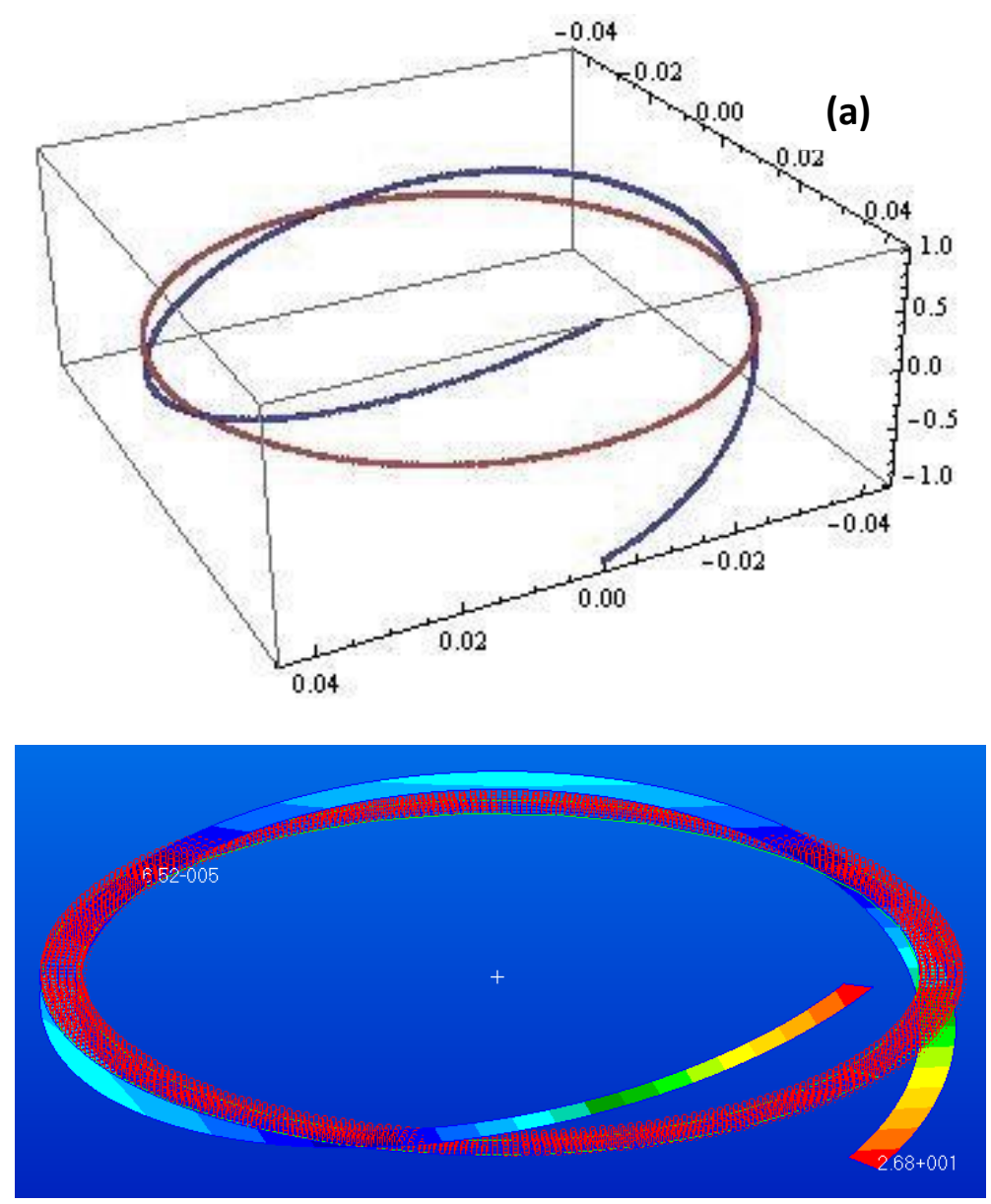

(b)

Figure 2: Example of the out-of-plane ring mode shapes for a ring with free-free boundary conditions: (a) Analytical method $(f=92.54 \mathrm{~Hz})$ and $(b)$ FEA model $(f=93.33 \mathrm{~Hz})$.

ii) Ring lubrication and friction

In the lubrication analysis of the piston ring-cylinder liner contact, fully flooded inlet conditions are assumed. The lubricant temperature is kept constant throughout the engine cycle. The temperature of the liner is found to be much higher than any generated temperature rise due to viscous shear of the lubricant in the short transit time through the small width of the contact, as demonstrated by Morris et al [31].

A commonly used assumption in the lubrication of compression ring-cylinder conjunction is that no side leakage of lubricant occurs circumferentially as the lubricant entrainment into the conjunction takes place along the axial direction of the piston (along the ring contact 
face-width). The Reynolds equation is derived from the classic Navier-Stokes equations keeping the most significant terms and corresponding to the following additional assumptions: (i) The pressure, density and viscosity are constant across the film's thickness and (ii) Inertia terms are neglected. Thus, Reynolds equation becomes:

$$
\frac{\partial}{\partial x}\left(\frac{\rho h^{3}}{\eta} \frac{\partial p}{\partial x}\right)+\frac{\partial}{\partial y}\left(\frac{\rho h^{3}}{\eta} \frac{\partial p}{\partial y}\right)=12\left(u_{a v} \frac{\partial}{\partial x}(\rho h)+\frac{\partial}{\partial t}(\rho h)\right)
$$

A two-dimensional finite difference discretisation method (FDM) is used to solve Reynolds equation, simultaneously with the film thickness relationship:

$$
h(x, \beta, t)=h_{m}(t)+s(x)+w(\beta, t)
$$

where, $s(x)=a x^{6}+b x^{5}+c x^{4}+d x^{3}+e x^{2}+f x+g$ is the profile of the ring facewidth for the type of engine under investigation (described later) [13]. To include cavitation, Swift-Stieber boundary conditions were used, which sets any negative pressure developed in the contact to the cavitation pressure and also assumes that the pressure gradient vanishes at the lubricant film rupture boundary [13]. $h_{m}$ represents the minimum film thickness at a given time step and $\beta$ is the angle of twist. Ring twist also affects its axial contacting profile with the surface of the bore. For a tilt angle $\beta$ (determined through outof-plane ring dynamic analysis), a simple co-ordinate transformation is used to obtain the instantaneous contacting profile as: $s(x, y)=x \sin \beta+s(x) \cos \beta$.

Additionally, the variation of lubricant bulk rheology (density and viscosity) with generated pressures and temperature is also taken into account as:

For density [32]:

$$
\rho=\rho_{0}\left(1-0.65 \times 10^{-3} \Delta \theta\right)\left[1+\frac{6 \times 10^{-10}\left(p-P_{a t m}\right)}{1+1.7 \times 10^{-9}\left(p-P_{a t m}\right)}\right]
$$


For viscosity [33]:

$$
\eta=\eta_{0} \exp \left\{\left(\ln \eta_{0}+9.67\right)\left[\left(\frac{\Theta-138}{\Theta_{0}-138}\right)^{-S_{0}}\left(1+\frac{p-P_{a t m}}{1.98 \times 10^{8}}\right)^{Z}-1\right]\right\}
$$

where: $\Theta=\theta+273$ and $\Theta_{0}=\theta_{0}+273$, and:

$$
Z=\frac{\alpha_{0}}{5.1 \times 10^{-9}\left[\ln \left(\eta_{0}\right)+9.67\right]} \text { and } S_{0}=\frac{\beta_{0}\left(\Theta_{0}-138\right)}{\ln \left(\eta_{0}\right)+9.67}
$$

An initial guess is made for the minimum gap $h_{m}(t)$ which alters during the Gauss-Seidel iterative procedure using over-relaxation through which the generated pressure distribution is obtained at any instant of time (corresponding to a given crank angle location):

$$
p_{i, j}^{n}=(1-\gamma) p_{i, j}^{o}+\gamma p_{i, j}^{n} \quad(0<\gamma<2)
$$

The relaxation factor $\gamma$ is problem-dependent. Pressure convergence at each node is achieved by using the following criterion:

$$
\operatorname{Err}_{\text {pressure }}=\frac{\sum_{i=1}^{I} \sum_{j=1}^{J}\left|p_{i, j}^{n}-p_{i, j}^{o}\right|}{\sum_{i=1}^{I} \sum_{j=1}^{J} p_{i, j}^{n}} \leq 1 \times 10^{-5}
$$

Once the pressure distribution is obtained, the hydrodynamic load carrying capacity produced by the ring, $W_{h}$, is obtained as:

$$
W_{h}=\iint p d A
$$

With thin films, there is an increasing chance of direct interaction of asperities on the contiguous surfaces. Therefore, at least in parts of the engine cycle a mixed regime of lubrication is anticipated. For an assumed Gaussian distribution of asperities, Greenwood and Tripp [34] proposed a model for calculating the contacting asperity loads [34]:

$$
W_{a}=\frac{16 \sqrt{2}}{15} \pi(\zeta \kappa \sigma)^{2} \sqrt{\frac{\sigma}{\kappa}} E^{\prime} A F_{5 / 2}\left(\lambda_{s}\right)
$$


In equation (39), the terms $(\zeta \kappa \sigma)$ and $(\sigma / \kappa)$ are the dimensionless roughness parameters obtained through surface roughness measurements. $\kappa$ is the average asperity radius of curvature, $\zeta$ is the number of asperity peaks per unit area and $\sigma$ represents the composite surface roughness. $A$ is the apparent contact area (the assumed smooth ring face-width contact area, prior to the inclusion of surface roughness). $\lambda_{s}$ is the Stribeck film ratio, being the ratio of film thickness to the average surface roughness. $F_{5 / 2}\left(\lambda_{s}\right)$ is the probability distribution of asperity heights. In this study, this is approximated by a fifth-order polynomial curve [35]:

$$
F_{5 / 2}(\lambda)=-0.0046 \lambda_{s}{ }^{5}+0.0574 \lambda_{s}{ }^{4}-0.2958 \lambda_{s}{ }^{3}+0.7844 \lambda_{s}{ }^{2}-1.0776 \lambda_{s}+0.6167(40)
$$

Total contact ring-liner friction is as the result of viscous shear of the lubricant and any direct boundary interactions:

$$
f_{t}=f_{v}+f_{b}
$$

Styles et al [36] presented the boundary friction as:

$$
f_{b}=\tau_{0} A_{e}+\xi W_{a}
$$

where, $\tau_{0}$ is the lubricant limiting Eyring stress and $\xi$ the pressure coefficient of boundary shear strength of surface asperities. Styles et al [36] measured this parameter for the coated material of the ring contacting face, used in the current study. The values were 0.3038 and 0.2012 for a new and an end-of-life ring [36]. $A_{e}$ is the effective asperity contact area, accounting for the summation of contact areas at the tip of asperities [35]:

$$
A_{e}=\pi^{2}(\zeta \kappa \sigma)^{2} A F_{2}\left(\lambda_{s}\right)
$$

Viscous component of overall friction is:

$$
f_{v}=\tau\left(A-A_{e}\right)
$$


where $\tau$ is the viscous shear stress of the lubricant:

$$
\tau=\left(\tau_{x}^{2}+\tau_{y}^{2}\right)^{1 / 2}=\left| \pm \frac{h}{2} \vec{\nabla} p+\vec{V} \frac{\eta}{h}\right|
$$

The ring dynamic response for both the in-plane $[24,25]$ and out-of-plane cases includes a forcing term, which incorporates any excitation applied to the relevant ring plane. This force profile is extracted from the tribological analysis post calculation of the external and internal forces acting upon the ring, as shown in Figure 3 for the ring's cross-section. Considering inplane dynamics, it can be seen that the forces acting on the ring include: elastic (ring tension) force, $F_{e}$, the combustion gas force, $F_{g}$, and the contact reactions; $W_{h}, W_{a}$. The approach with which the out-of-plane methodology is coupled to the tribological analysis differs slightly from the in-plane case. The following relation in the out-of-plane direction is derived from the free body diagram of figure 3 :

$$
\sum F_{x}=F_{g}+m g-f_{v}-f_{b}-R_{g}=F_{A}
$$

where, $F_{A}$ is the resultant out-of-plane force acting upon the ring.

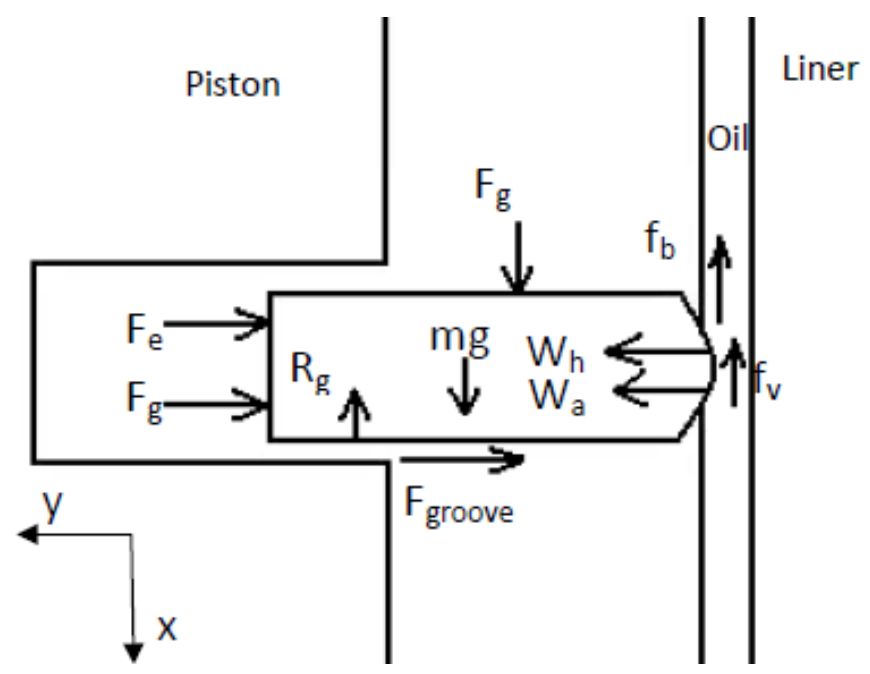

Figure 3: Free body diagram for a cross-section of the top compression ring 
The ring's weight is negligible when compared with the gas force, with a typical weight of approximately $0.05 \mathrm{~N}$. The reaction force from the piston groove acting upon the ring, $R_{g}$ is calculated using Tian's method [6]. A layer of lubricant is assumed to be present on the groove's surface. Tian [6] solved the one-dimensional Reynolds' equation in pure squeeze, where $h$ here is the thickness of any film of lubricant in the ring-groove land conjunction:

$$
\frac{\partial}{\partial x}\left(\frac{h^{3}}{\eta} \frac{\partial p_{g v}}{\partial y}\right)=12 \frac{\partial h}{\partial t}
$$

As it can be seen, this approach neglects the effect of any sliding between the ring and the groove face. If the ring is assumed to be rigid, then this assumption can be upheld. However, with in-plane dynamics included, some sliding occurs as the result of ring in-plane motion relative to the groove land. Therefore, equation (47) becomes:

$$
\frac{\partial}{\partial x}\left(\frac{h^{3}}{\eta} \frac{\partial p_{g v}}{\partial y}\right)=6 \frac{\partial w(\varphi, t)}{\partial t} \frac{\partial h}{\partial y}+12 \frac{\partial h}{\partial t}
$$

The solution of equation (48) gives the generated conjunctional pressure. The contact reaction becomes:

$$
R_{g}=\int p_{g v} d y
$$

It should be noted that term $F_{g}$ is the net gas force, which is the difference between the cylinder and crankcase gas applied pressures. The crankcase pressure is assumed to be equal to the atmospheric pressure for this analysis, although an inter-ring gas pressure model can replace this for a more realistic approach, which would affect the boundary conditions for Reynolds equation. For this purpose a gas blow-by model would be required, such as that presented in Baker et al [37]. 
iii) Solution procedure.

Figure 4 shows a flowchart of the solution steps for the coupling of ring dynamics with tribology in both the ring-bore and ring-groove land conjunctions. This extends the work of Baker et al $[24,25]$. A summary of the solution procedure is as follows:

- At each crank angle increment, the ring dynamics' model extracts the net force profiles acting upon the ring.

- The deformed ring profile is then calculated using the external excitation and returns to the tribological analysis. The circumferential film profile is then updated, as are the localised velocity values.

- The converged values from the previous step are provided as initial conditions for the next crank angle increment.

The solution time for each engine speed case can be over 24 hours, due to the small time step discretisation which is necessary at piston reversals, high pressures and temperatures. This enables the ring to respond elastically to the applied loads and provides a high resolution output. It can clearly be seen that any in-plane motion of the ring would affect its out-of-plane motion and vice-versa. For example, the in-plane ring dynamics influences the lubricant film thickness (equation (32)), thus the generated ring-bore friction. Additionally, the ring's axial velocity as the result ring's out-of-plane dynamics affects the in-plane lubricant reaction force. However, the mathematical solution for transient ring dynamics shows that the in-plane and out-of-plane equations of motion have no common degrees of freedom, and so can be solved separately. The coupling is through the tribological contact conditions. 


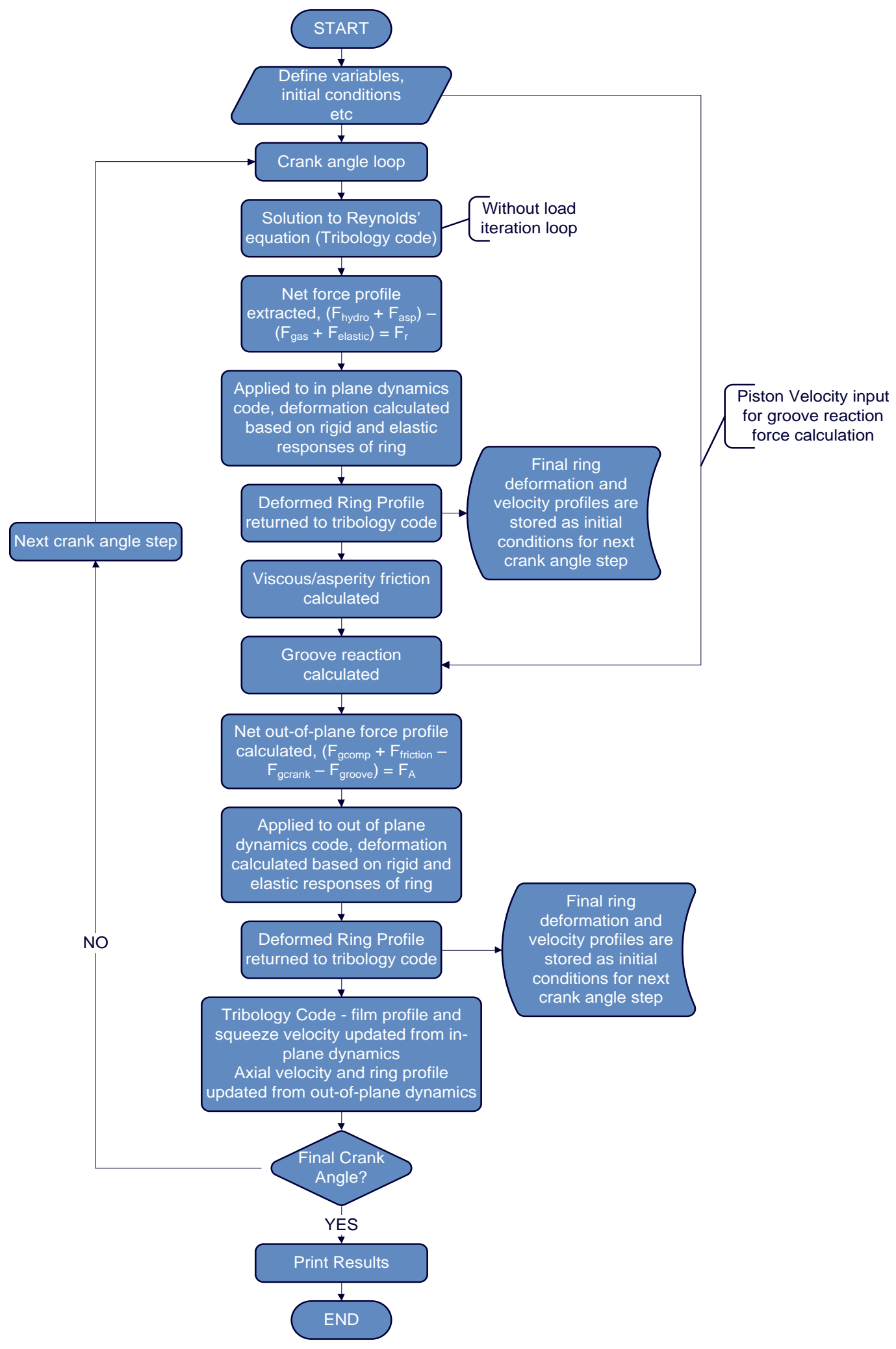

Figure 4: Coupled tribodynamics model for the three dimensional motion of the compression ring 


\section{Results and discussion}

\section{i) System specifications}

The system analysed is based on a cylinder of a high performance V12 gasoline engine with a maximum power output of $510 \mathrm{BHP}$. Each cylinder has a stroke of $80 \mathrm{~mm}$, and a bore radius of $44.5 \mathrm{~mm}$. The lubricant used in the analysis is SAE 10W40. Table 2 lists the lubricant rheological parameters. The ring surface roughness parameters used in calculation of boundary friction are listed in Table 3. These data are obtained through topographical measurements using the Alicona Infinite Focus Microscope (IFM). The compression ring dimensions and material properties are provided in Table 4.

Table 2: Lubricant Parameters

\begin{tabular}{ccc}
\hline Parameter & Value & Unit \\
\hline Pressure-viscosity coefficient & $2 \times 10^{-8}$ & $\mathrm{~m}^{2} / \mathrm{N}$ \\
Thermal expansion coefficient & $6.5 \times 10^{-4}$ & $1 /{ }^{\circ} \mathrm{K}$ \\
Lubricant density & 833.8 at $40\left[{ }^{\circ} \mathrm{C}\right], 783.8$ at $100\left[{ }^{\circ} \mathrm{C}\right]$ & $\mathrm{kg} / \mathrm{m}^{3}$ \\
Lubricant kinematic viscosity & 59.99 at $40\left[{ }^{\circ} \mathrm{C}\right], 9.59$ at $100\left[{ }^{\circ} \mathrm{C}\right]$ & $\times 10^{-6} \mathrm{~m}^{2} / \mathrm{s}$ \\
\hline
\end{tabular}

Table 3: Ring surface roughness parameters used in the boundary friction model

\begin{tabular}{ccc}
\hline Parameter & Value & Unit \\
\hline Ra for the liner & 0.26 & $\mu \mathrm{m}$ \\
Ra for a new ring & 0.408 & $\mu \mathrm{m}$ \\
Roughness parameter $\left(\zeta \mathrm{K} \sigma_{\mathrm{c}}\right)_{c}$ & 0.074 & - \\
Measure of asperity gradient $\left(\sigma_{\mathrm{c}} / \mathrm{k}\right)_{\mathrm{c}}$ & 0.309 & - \\
\hline
\end{tabular}

Table 4: Compression ring dimensions and material properties

\begin{tabular}{ll}
\hline Property & Value \\
\hline Elastic modulus & $203 \mathrm{GPa}$ \\
\hline
\end{tabular}




\begin{tabular}{ll}
\hline Ring density & $7800 \mathrm{~kg} / \mathrm{m}^{3}$ \\
\hline Ring thickness & $3.5 \mathrm{~mm}$ \\
\hline Axial face-width & $1.15 \mathrm{~mm}$ \\
Nominal fitted ring radius & $44.52 \mathrm{~mm}$ \\
\hline Ring second moment of area & $2.25 \times 10^{-12} \mathrm{~m}^{4}$ \\
Ring end gap size (free ring) & $10.5 \mathrm{~mm}$ \\
\hline
\end{tabular}

ii) Predictions for the engine under consideration

The methodology presented is used for the tribo-dynamic analysis of an engine with the specifications provided in Tables 2-4.

Figure 5 depicts the ring axial displacement within the groove for a complete cycle at low engine speed. For each crank angle increment, the displacement corresponding to the whole compression ring profile has been plotted. This enables the reader to appreciate the overall ring motion (rigid body), as well as the elasticity of the ring at each crank angle. At $0^{\circ}$ (TDC), the range of the ring deflection is within approximately $1 \mu \mathrm{m}$. However, when the ring has been forced away from the top groove face at approximately $30^{\circ}$ past TDC, the range of deflection can be seen to be of the order of tens of micrometres (as demonstrated by the three-dimensional insert of figure 5). A qualitatively similar trend has been observed in the experimental measurements of Takiguchi [26], as well as by Namazian and Heywood [14]. The ring's sealing capability (its conformity to the groove land to reduce pressure loss) can be compromised when the combustion pressure is sufficient to force the ring away from the upper groove land. Takiguchi [26] observed that in some low-speed cases, the ring remained in contact with the lower groove face throughout the combustion event. The results presented in the current work qualitatively agree with those of Takiguchi (at approximately 2000rpm) [26]. As with the ring-to-liner film thickness comparison, there is a difference 
between the contact in the thrust and anti-thrust sides, which could not be monitored by the experimental set up by Takiguchi et al [26].

At the point of maximum pressure in this gasoline engine (crank angle of $22^{\circ}$ ), the ring is forced away from the top groove land, which would result in loss of sealing. The corresponding ring modal shape is shown in the inset to figure 5 . The same trend is noted in Takiguchi's results at higher engine speeds (2400rpm). Engine speeds above 2400rpm show more stable behaviour in terms of ring out-of-plane motion [26]; the combustion pressure is unable to overcome the piston inertial dynamics effect on the ring. The ring's axial position changes between the crank angles $180^{\circ}$ and $540^{\circ}$ in figure 6 , with minimal loss of sealing.

Figure 6 demonstrates the ring's elastic deformation as it is forced away from the top groove face (at approximately $24^{\circ}$ past TDC in figure 5 ). It can be seen that the elastic deformation becomes more pronounced as the ring is forced away from the top groove face. When the ring is not pressed against the piston groove, the flexibility of the ring becomes a greater influence on the forced response of the ring.

Figure 7 shows the frictional power loss variations calculated using an assumed rigid ring, an in-plane elastic ring (only), and a fully 3D dynamics case. The engine speed and lubricant temperature are $1000 \mathrm{rpm}$ and $40^{\circ} \mathrm{C}$, respectively. These correspond to cold start-up conditions which are often used as a part of New European Drive cycle (NEDC) for emission testing. Increased asperity interactions appear as the "spikes" in frictional power loss around the TDC and BDC. This is especially noticeable away from the high pressure reversal point just before combustion. The squeeze effect caused by ring in-plane dynamics may also promote further asperity interactions, thus increase the power loss around the firing point, even for comparable minimum film thickness predictions. 

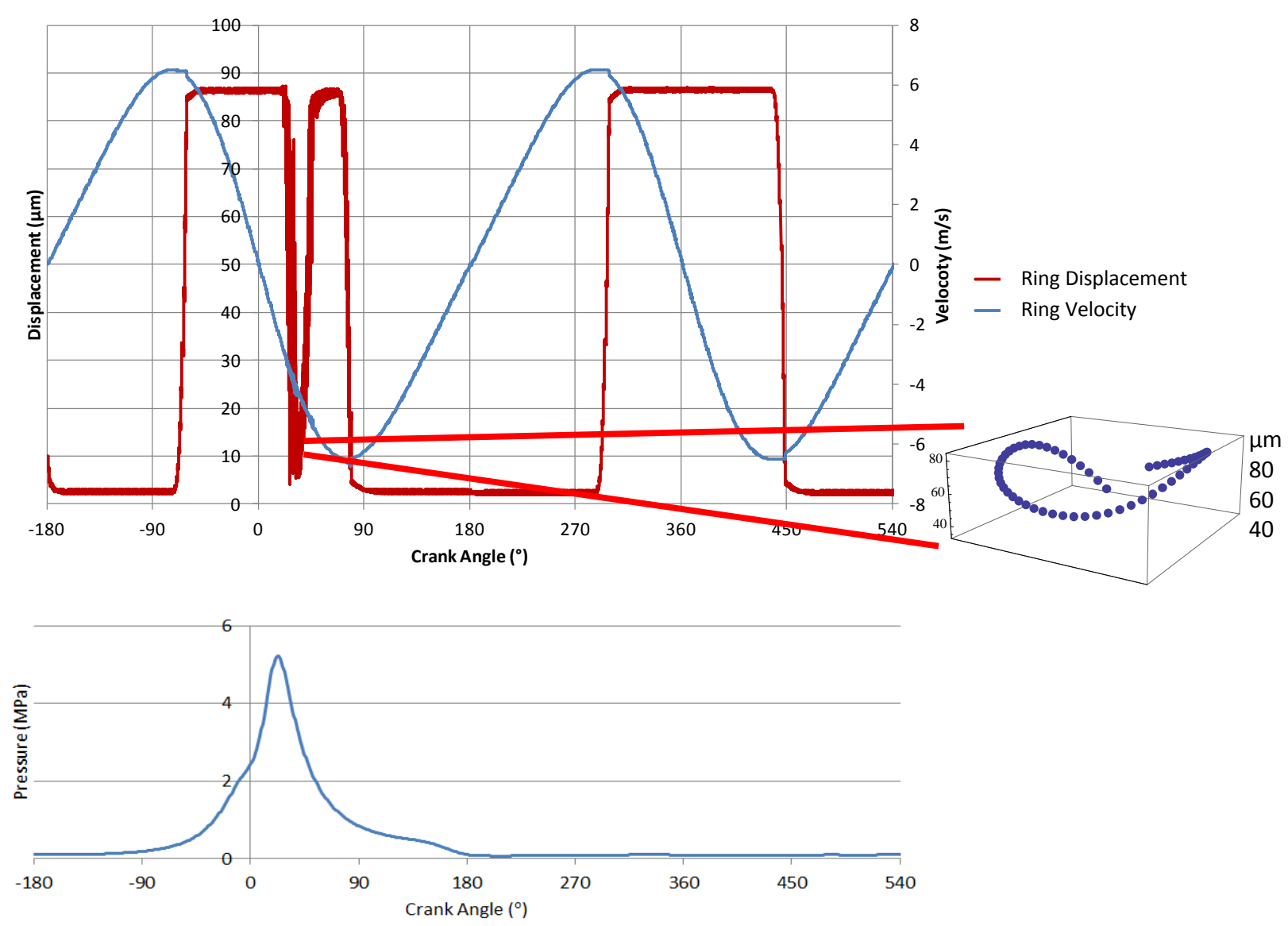

Figure 5: Ring out-of-plane axial position throughout the engine cycle, alongside ring axial velocity and cylinder gas pressure (Engine speed $=1500 \mathrm{rpm}$, lubricant temperature $=120^{\circ} \mathrm{C}$ at full throttle)

Figures 8 and 9 present the overall ring axial motion at $1000 \mathrm{rpm}$, as well as the threedimensional response of the ring as it is forced to the bottom groove face. Again, significant elastic behaviour is seen during the transition from one groove face to the other. Such a dramatic ring deformation could indicate potential ring flutter and blowby issues, as increased elastic response can lead to ring instability and the loss of sealing.

Figures 10 and 11 show the friction power loss and ring displacement at higher engine speed (2000rpm). The inclusion of ring dynamics in both planes gives very similar friction power results to those with that just including the in-plane ring dynamics. This suggests that 
when assessing the frictional power loss associated with the top compression ring, the inclusion of out-of-plane ring dynamics may have less effect as the engine speed increases. Here the in-plane and out-of-plane ring dynamic methodologies have been applied in a decoupled manner. Therefore, the consideration of the out-of-plane ring dynamics does not seem to have a significant effect on the tribological performance (when compared with the effect of in-plane dynamics only), particularly with high liner temperature resulting in thin lubricant films.

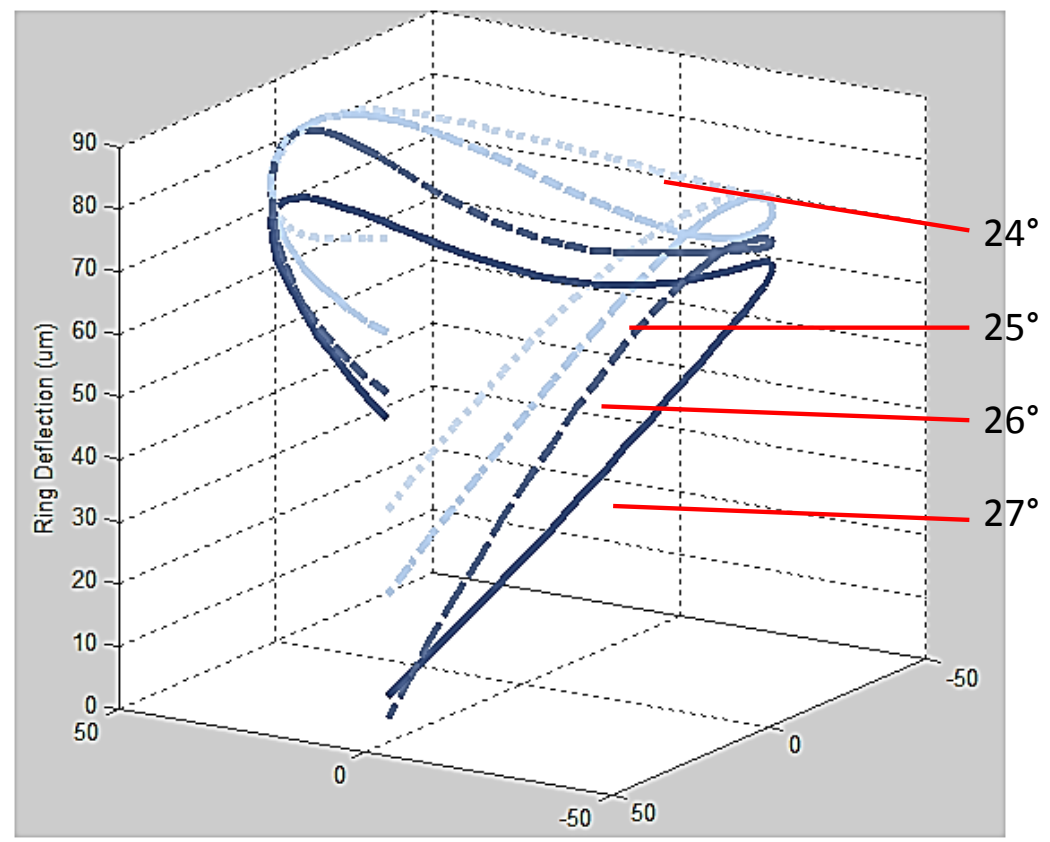

Figure 6: Three-dimensional ring deformation at the point of maximum cylinder pressure, (Engine speed $=1500 \mathrm{rpm}$, lubricant temperature $=120^{\circ} \mathrm{C}$ at full throttle) 


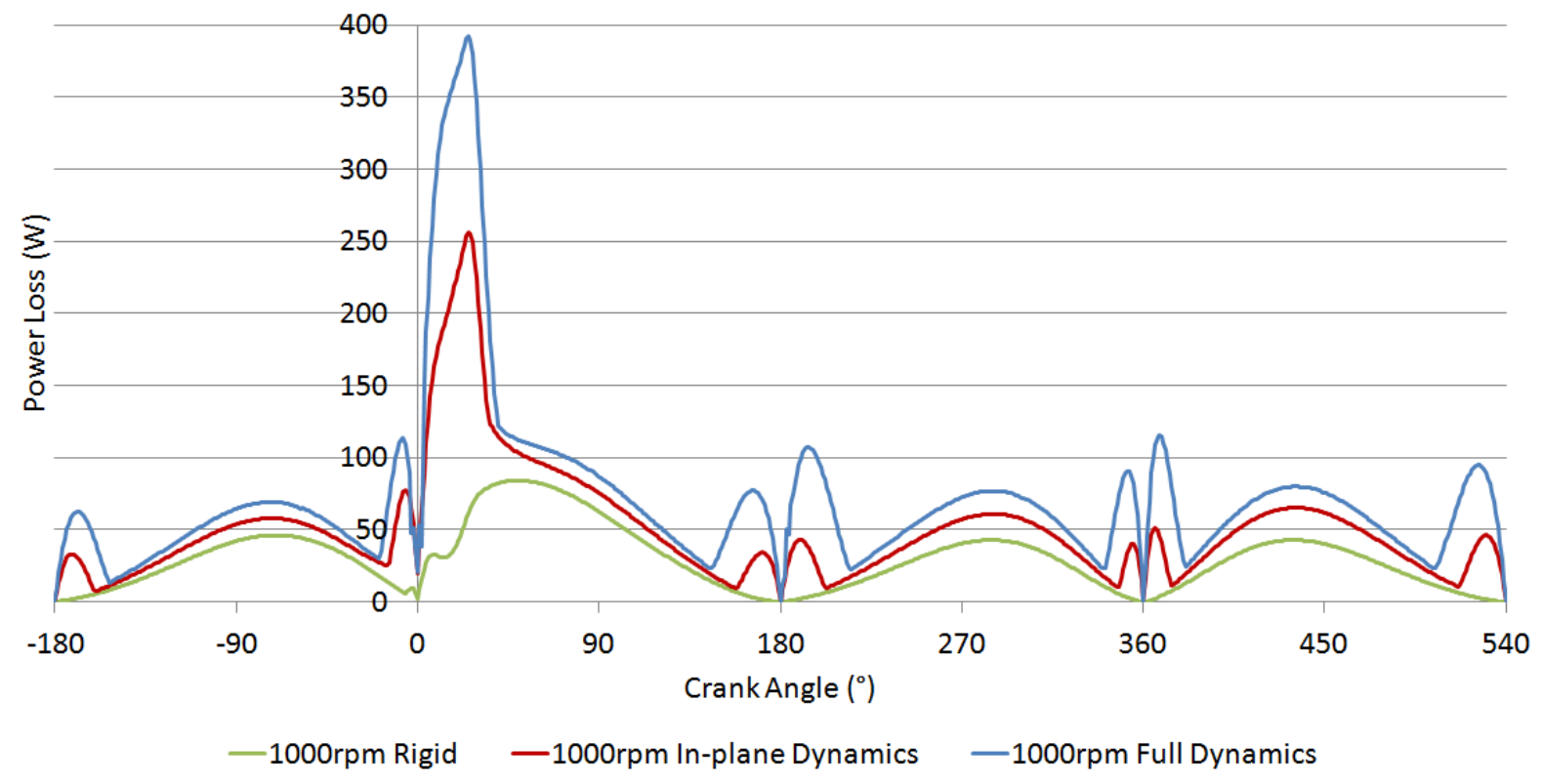

Figure 7: Total friction power loss for rigid, in-plane elastic and fully elastic models of the compression ring at $1000 \mathrm{rpm}$ with lubricant temperature of $40^{\circ} \mathrm{C}$, part throttle

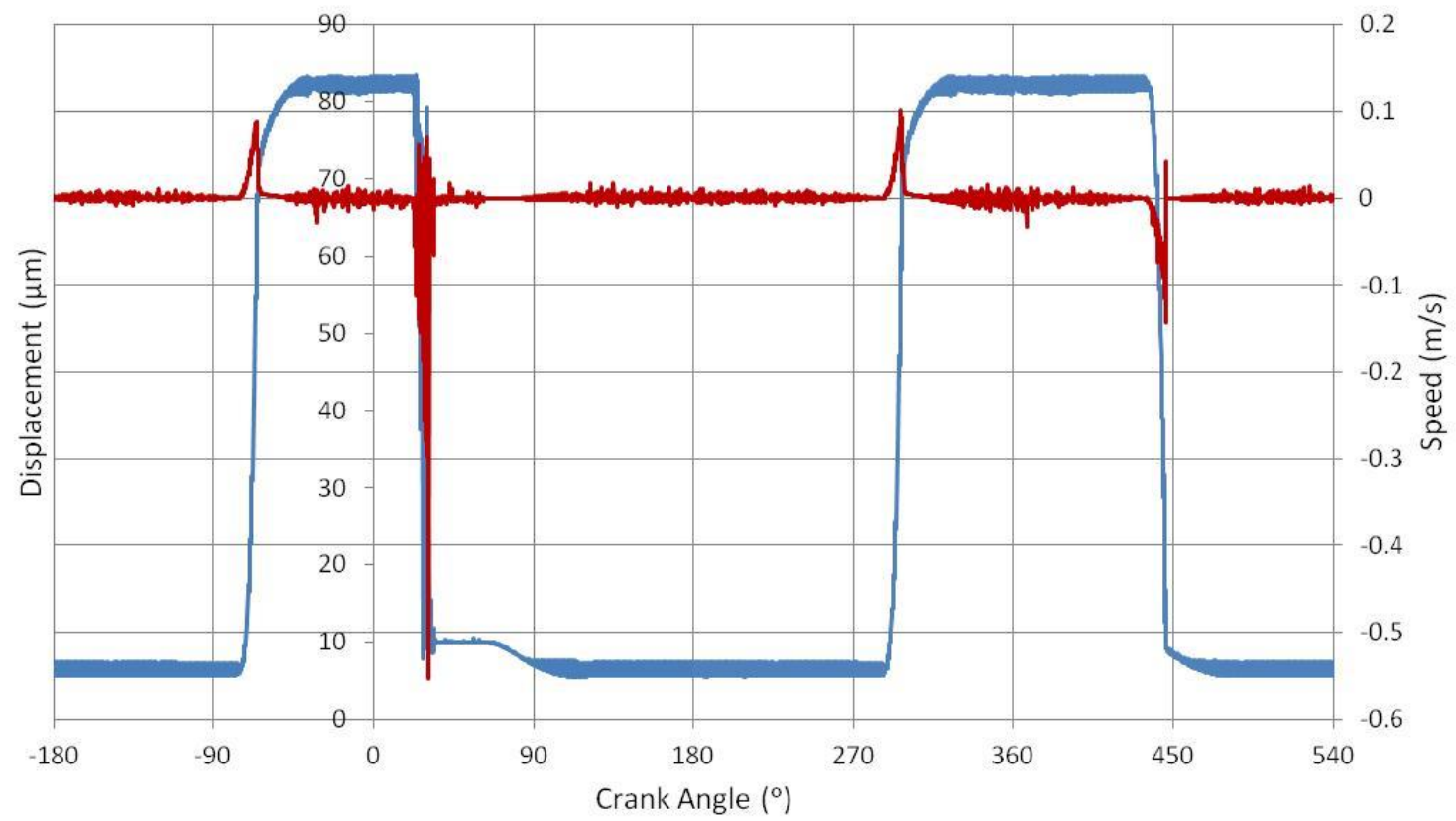

—Groove Displacement — Ring Net Velocity

Figure 8: Ring out-of-plane axial position throughout the engine cycle, alongside ring axial velocity and cylinder gas pressure (Engine speed $=1000 \mathrm{rpm}$, lubricant temperature $=40^{\circ} \mathrm{C}$ ) 


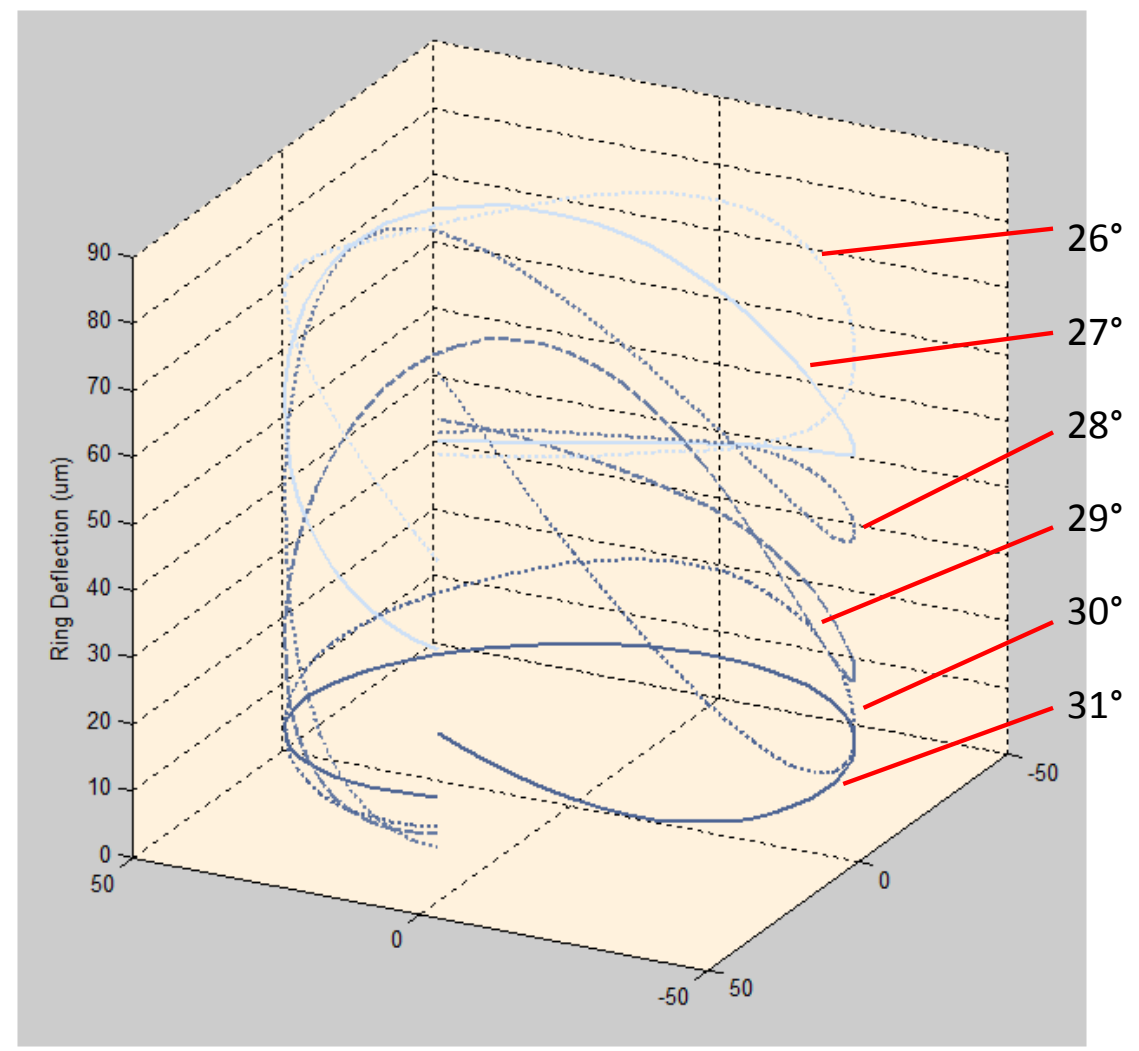

Figure 9: Three-dimensional ring deflection during the power stroke (Engine speed = $1000 \mathrm{rpm}$, lubricant temperature $=40^{\circ} \mathrm{C}$, part throttle)

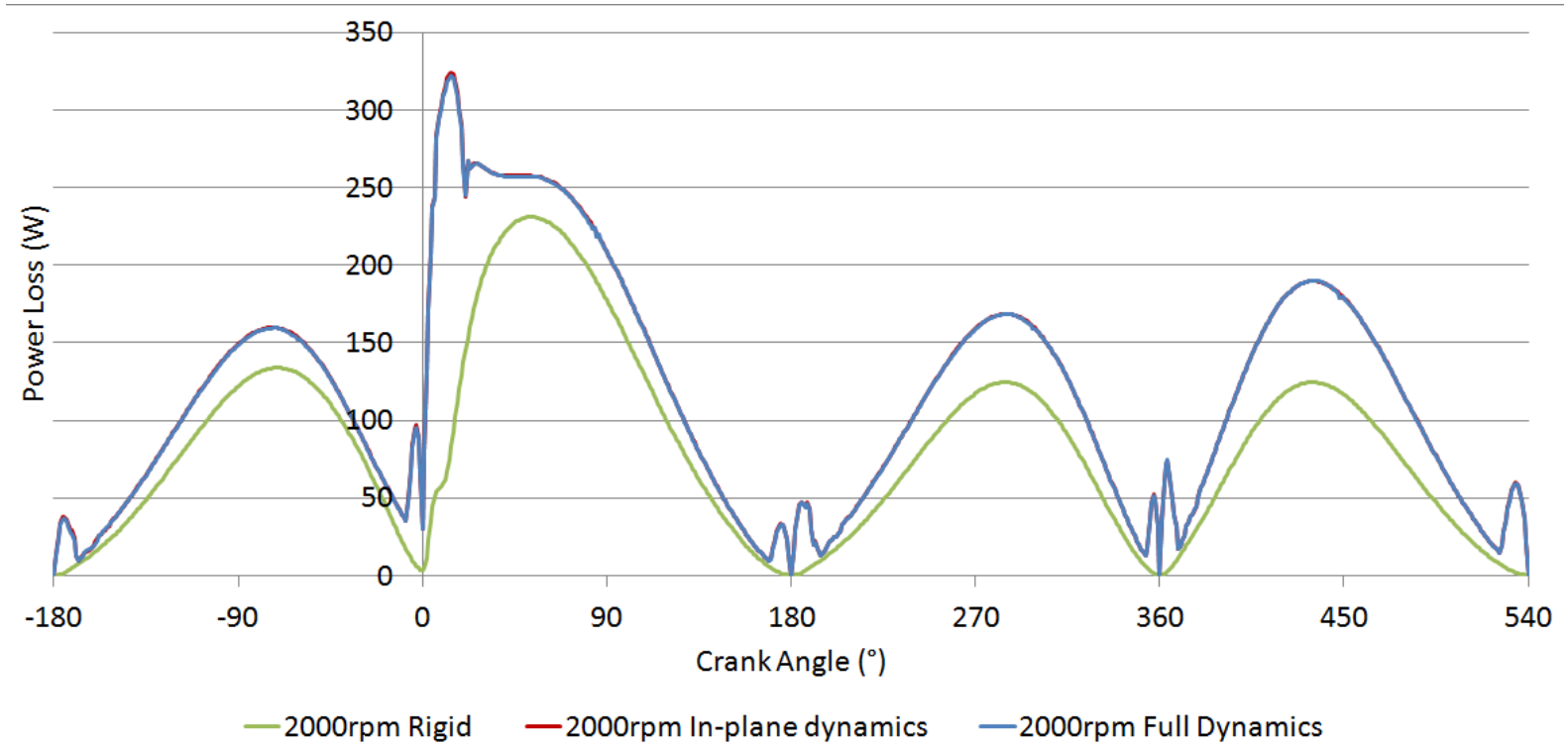

Figure 10: Total frictional power loss comparisons for a rigid ring, an in-plane elastic ring and a full dynamic one at $2000 \mathrm{rpm}$, with lubricant temperature of $40^{\circ} \mathrm{C}$ (part throttle) 
Figure 12 shows a comparison of the friction power loss predicted for the cases of rigid and deformed rings (in-plane dynamics and fully transient cases), corresponding to higher lubricant temperatures of $120^{\circ} \mathrm{C}$. This represents the temperature of the cylinder liner under the hot steady state part of the NEDC in low speed urban driving condition. The presented methodology does not include any gas flow prediction through the ring pack, which in the case of out-of-plane ring dynamics would alter as the ring moves from the lower groove land to its top land. This would subsequently further affect the lubricant film thickness.

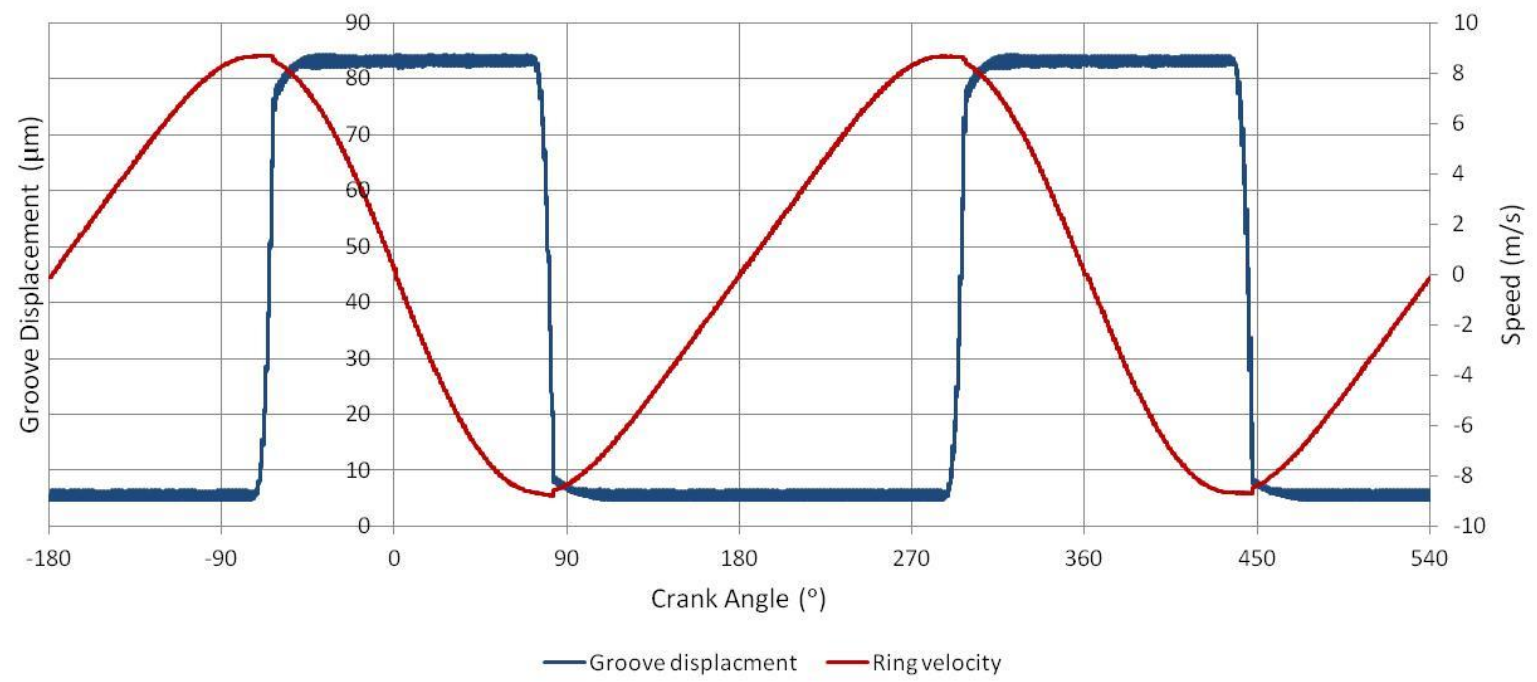

Figure 11: Ring out-of-plane axial position throughout the engine cycle, alongside ring axial velocity at $2000 \mathrm{rpm}$, with lubricant temperature of $40^{\circ} \mathrm{C}$ 


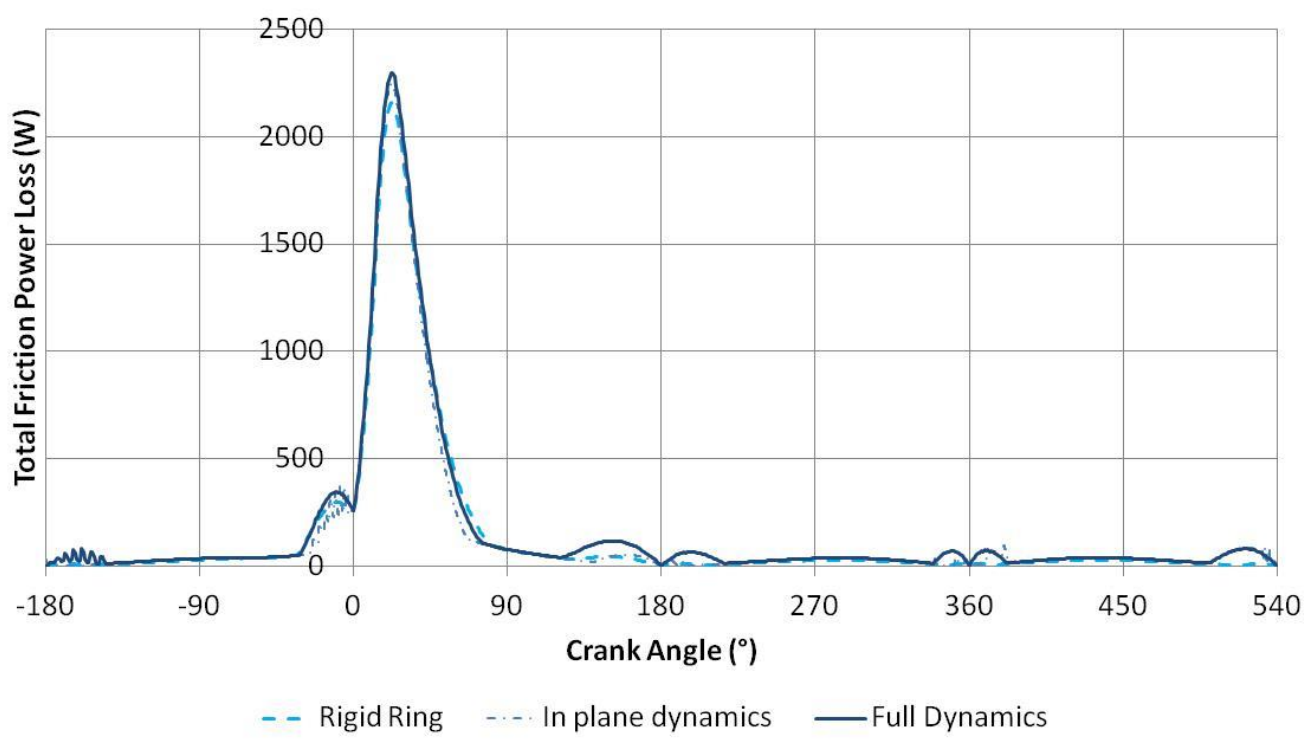

Figure 12: Friction power loss comparison for a rigid ring, an in-plane elastic ring and a fully dynamic ring at the engine speed of $2000 \mathrm{rpm}$ with lubricant temperature of $120^{\circ} \mathrm{C}$ (fullthrottle)

The inclusion of out-of-plane ring dynamics allows for any lateral/axial ring motion with respect to the piston. Although the piston groove restricts the ring's motion in the axial piston direction, there is room for the ring to move rigidly and elastically during the engine cycle. From the engine data available, a gap of tens of micrometres remains between the ring and its retaining groove lands. It is assumed that a layer of lubricant would be present on both the groove lands. Using the method proposed by Tian [6], the groove lubricant reaction is calculated when the gap between the ring and the groove becomes less than $10 \mu \mathrm{m}$ as a fully flooded condition is assumed. If the gap is greater, then the cylinder (top of the ring) or crankcase (bottom of the ring) pressure is used in the calculations.

The minimum film thickness predictions of both the in-plane and fully dynamic analyses show good agreement with each other. The in-plane analysis has a significantly reduced solution time due to the lower complexity of the dynamics. In some cases, where the 
motion of the ring within the groove is not of interest, it may be sufficient to run an in-plane only analysis across a full speed sweep.

Figure 13 shows the position of the ring within the groove throughout the engine cycle at 1500rpm, alongside the difference in axial velocity of the ring and its instantaneous displacement. The displacement is presented in the same way as in figure 5 , with each crank angle increment showing the ring response at each circumferential response. The ring velocity variation is shown in figure $13 \mathrm{~b}$, and is seen to largely follow the piston's velocity profile, as would be expected. However, in the instances immediately after the point of maximum velocity in each stroke, there is a small deviation from an otherwise smooth

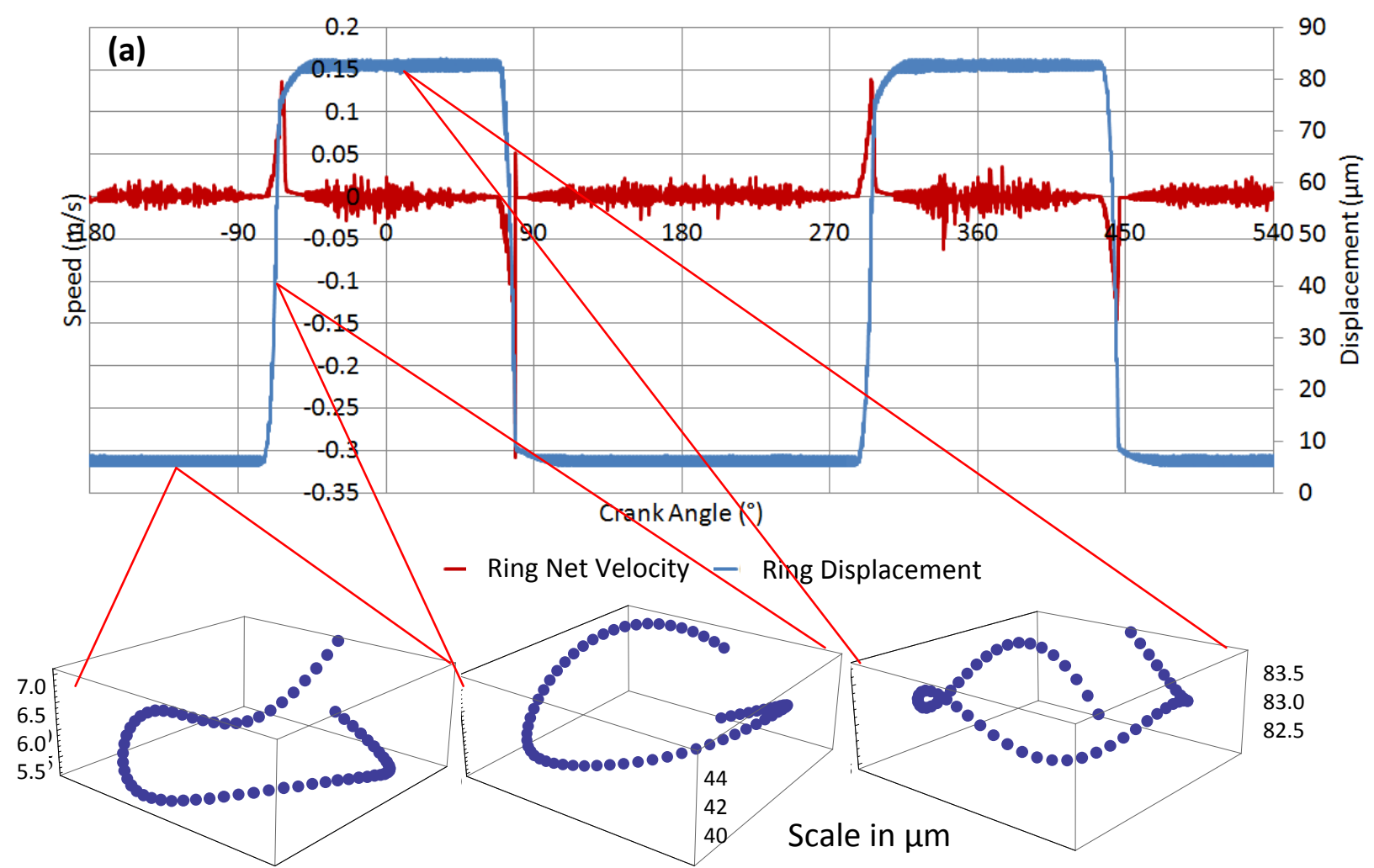




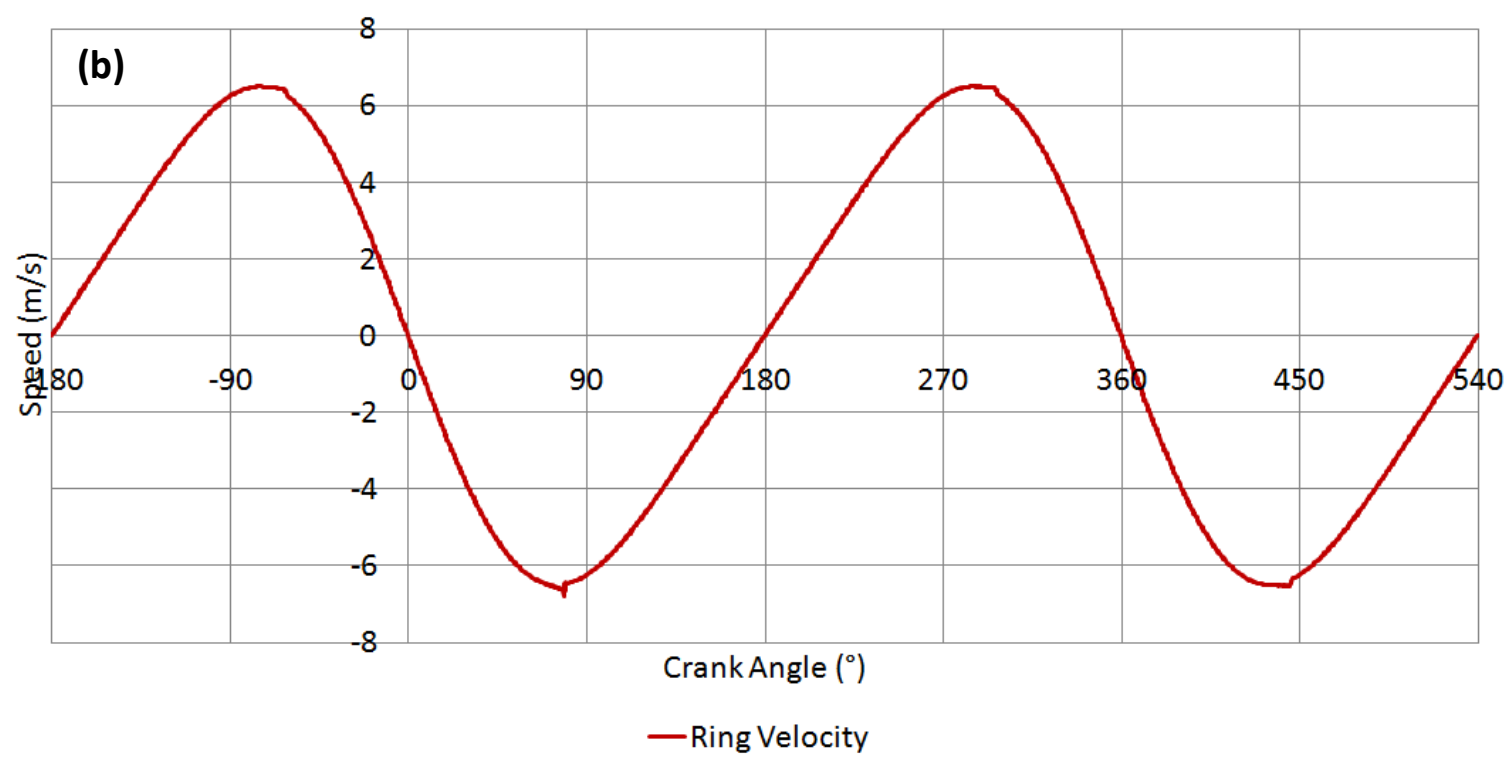

(b)

Figure 13: (a) Compression ring axial groove position and three dimensional ring profiles within the piston groove; (b) ring velocity variation (Engine speed $=1500 \mathrm{rpm}$, lubricant temperature $=40^{\circ} \mathrm{C}$ )

curve. These 'spikes' are shown in the net velocity results in figure 13a and occur due to piston's axial velocity slowing upon approaching the dead centres prior to reversal. The compression ring continues moving at a higher velocity and loses contact with the piston groove land. As the ring approaches the opposite face of the groove, the lubricant present there creates a reaction force, slowing the ring so that it once again follows the velocity profile of the piston, with some slight localised variations. The motion of the ring away from either of the groove lands may cause loss of sealing (some gas pressure is expected to be lost through the gap behind the ring). This would increase the probability of ring axial oscillations (flutter) and blow-by. Figure 13 also shows examples of ring deformation at different positions throughout the engine cycle. Note the scale in each of the deformed ring profiles, which suggests that there is greater deformation when the ring is in transition between the two groove lands. This can be expected due to the groove reaction against the 
ring, which would reduce its elastic displacement. Figure $13 \mathrm{~b}$ shows that the ring largely follows the axial velocity of the piston with reduced elastic body response.

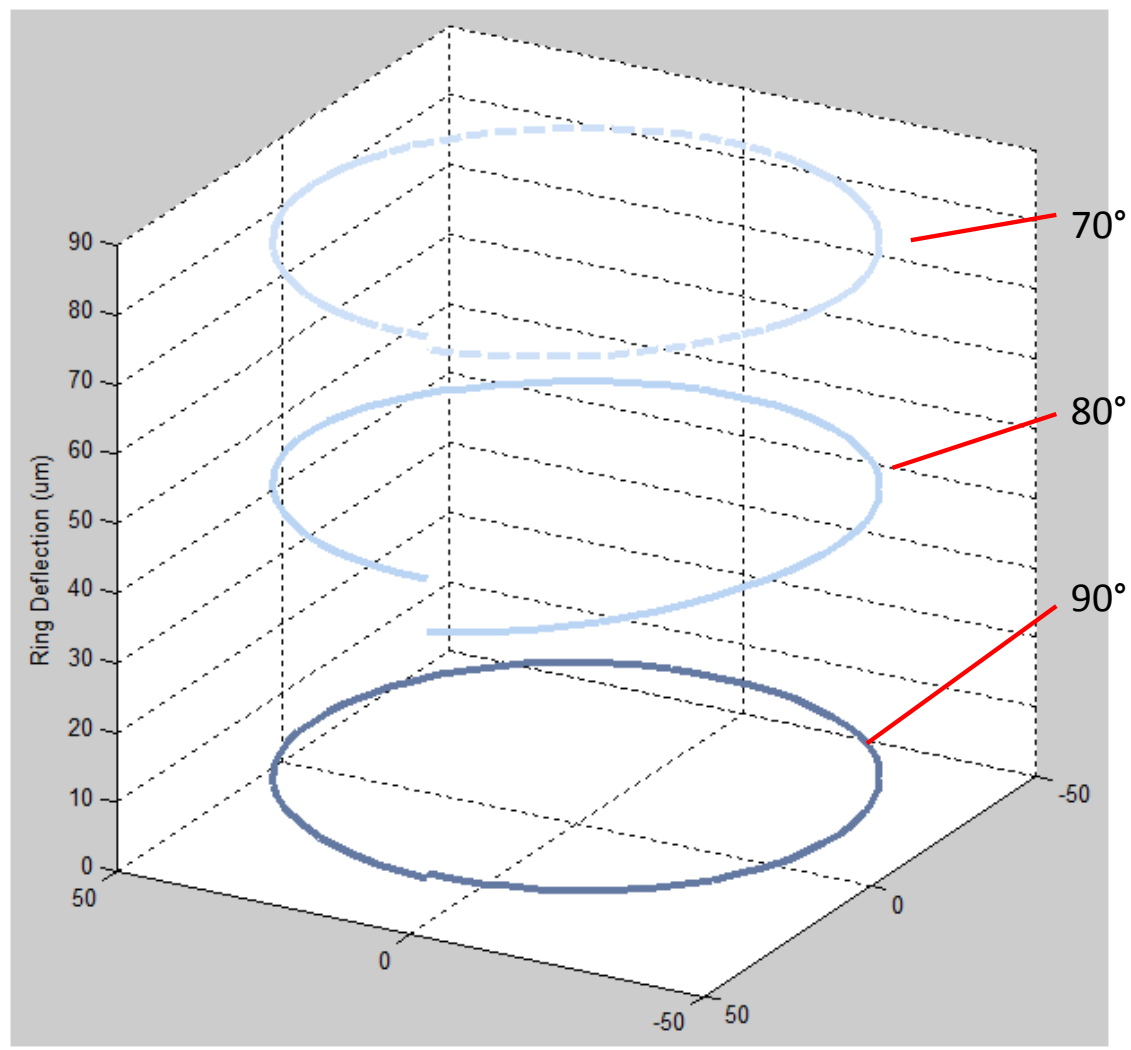

Figure 14: Compression ring axial groove position and three dimensional ring profiles within the piston groove (Engine speed $=1500 \mathrm{rpm}$, lubricant temperature $=40^{\circ} \mathrm{C}$ )

Further three-dimensional results of the ring are shown in figure 14 . These correspond to snapshots of the engine cycle before, during and after the ring has moved from one groove face to the other. In contrast to figures 6 and 9, the ring's elastic deformation is much less apparent, with the rigid body motion dominating the response. As the ring's inertial forces (applied by the piston during its translation through the liner) are not overcome by the cylinder pressure, the loading on the ring does not cause the elastic response previously seen. This response would suggest a more stable ring pack, with lower risk of flutter and blowby occurring. 


\section{Conclusions}

A tribological model, incorporating three-dimensional transient elastodynamics of the transient compression ring has been presented. In particular, the out-of-plane ring elastodynamics are described in detail, including its transient response, alongside verification of the modal features against a finite element model. The coupling mechanism between ring dynamics and tribology has not hitherto been reported in literature, accounting for the main contribution of the paper. The methodology is also verified against experimental work of other studies in open literature and shows reasonably good agreement.

Nevertheless, the numerical results obtained demonstrate the effect of ring dynamics on the tribological analysis of the compression ring. An increase in frictional power loss throughout the engine cycle is generally noted, as is the out-of-plane ring motion within the groove. This motion may have an effect on the ring-to-groove sealing, which has previously been demonstrated by the model predictions.

The observation of ring motion within the groove indicates the potential for the presented model to be further extended, or incorporated within a complete piston ring pack model. Gas flow, specifically blow-by, is an important issue when optimising the performance of engines. The ability to capture the ring's axial motion would facilitate the coupling of transient ring dynamics, tribology and gas flow, which would provide a significantly advanced ring pack model. The above constitute aspects for future work. In particular, the results for combined elastodynamics and tribological analyses present conditions of 
practical importance, already simulating conditions at cold start-up and hot steady state parts of the emission evaluation NEDC. Using the presented methodology, a more accurate prediction can be obtained ascertaining the effect of ring material, pre-tension and axial profile on its tribological performance. With a gas flow model, the gas flow through the ring pack can be analysed for various ring designs, with the optimum dynamic performance giving the lowest gas flow rate through the ring.

\section{Acknowledgements}

The authors wish to express their gratitude for the financial support of the Engineering and Physical Sciences Research Council for the Encyclopaedic Program Grant (EP/G012334/1), under auspices of which this research was carried out. Research data for this paper are available on request from Prof. Stephanos Theodossiades. Thanks are also due to all the industrial and academic partners of the Encyclopaedic project, in particular Aston Martin Lagonda.

\section{References}

[1] Smedley, "Piston Ring Design for Reduced Friction in Modern Internal Combustion Engines", Thesis, Massachusetts Inst. Technology, 2004

[2] Priest, M., and C. M. Taylor. "Automobile engine tribology-approaching the surface" Wear 241.2 (2000): 193-203.

[3] Furuhama, S., "A dynamic theory of piston-ring lubrication: 1st report, calculation", Bulletin of JSME, 2(7), 423-428 (1959)

[4] Furuhama, S., "A dynamic theory of piston-ring lubrication: 2st report, experiment", Bulletin of JSME, 3(10), 291-297 (1960) 
[5] Furuhama, S., "A dynamic theory of piston-ring lubrication: 3rd report, measurement of oil film thickness", Bulletin of JSME, 4(16), 744-752 (1961)

[6] Tian, T., Noordzij, L., Wong, V. W., and Heywood, J. B., "Modeling piston-ring dynamics, blowby, and ring-twist effects." ASME J Gas Turb Pwr 120.4 (1998): 843-854.

[7] Tian, T., "Dynamic behaviours of piston rings and their practical impact. Part 1: ring flutter and ring collapse and their effects on gas flow and oil transport." Proceedings of the Institution of Mechanical Engineers, Part J: Journal of Engineering Tribology 216.4 (2002): 209-228.

[8] Fox, M.F., Jones, C.J., Picken, D.J. and Stow, C.G., "The 'limits of lubrication' concept applied to the piston ring zone lubrication of modern engines." Tribology Letters 3.1 (1997): 99-106.

[9] Richardson, D. E. "Review of power cylinder friction for diesel engines." ASME J Gas Turb Pwr 122.4 (2000): 506-519.

[10] Andersson, P., Tamminen, J., and Sandström, C., "Piston ring tribology: A literature survey", VTT Tiedotteita-Research Notes 2178.1 (2002).

[11] Littlefair, B., De la Cruz, M., Theodossiades, S., Mills, R., Howell-Smith, S., Rahnejat, H. and Dwyer-Joyce, R.S., "Transient tribo-dynamics of thermo-elastic compliant highperformance piston skirts", Tribology Letters, 2014, 53: 51-70

[12] Littlefair, B., De La Cruz, M., Mills, R., Theodossiades, S., Rahnejat, H., Dwyer-Joyce, R., Howell-Smith, S., "Lubrication of a flexible piston skirt conjunction subjected to thermoelastic deformation: A combined numerical and experimental investigation", Proceedings of the Institution of Mechanical Engineers, Part J: Journal of Engineering Tribology, 2014, 228: 69-81

[13] Rahmani, R., Theodossiades, S., Rahnejat, H. and Fitzsimons, B., "Transient elastohydrodynamic lubrication of rough new or worn piston compression ring conjunction with an out-of-round cylinder bore", Proceedings of the Institution of Mechanical Engineers, Part J: Journal of Engineering Tribology, 2012, 226: 284-305

[14] Namazian, M. and Heywood, J.B., "Flow in the piston-cylinder-ring crevices of a sparkignition engine: effect on hydrocarbon emissions, efficiency and power", SAE Technical Paper, No. 820088, 1982.

[15] Hill, S.H. and Newman, B.A., "Piston ring designs for reduced friction", SAE Technical Paper, No. SAE-TP-841222, 1984

[16] Mishra, P. C., Rahnejat, H. and King, P.D., "Tribology of the ring-bore conjunction subject to a mixed regime of lubrication." Proceedings of the Institution of Mechanical Engineers, Part C: Journal of Mechanical Engineering Science, 2009, 223(4): 987-998. 
[17] Furuhama, S. and Sasaki, S., "New device for the measurement of piston frictional forces in small engines", SAE Technical Paper, No. 831284, 1983.

[18] Baker, C. E., Rahmani, R., Theodossiades, S. and Rahnejat, H., "Analytical Evaluation of Fitted Piston Compression Ring: Modal Behaviour and Frictional Assessment", SAE Technical Paper 2011-01-1535, 2011.

[19] Dowson, D., Economou, P. N., Ruddy, B. L., Strachan, P. J., and Baker, A. J. S., "Piston ring lubrication. Part II: theoretical analysis of a single ring and a complete ring pack." Energy Conservation through fluid film lubrication technology: Frontiers in research and design (1979): 23-52.

[20] Tian, T., "Dynamic behaviours of piston rings and their practical impact. Part 2: oil transport, friction and wear of ring/liner interface and the effects of piston and ring dynamics." Proceedings of the Institution of Mechanical Engineers, Part J: Journal of Engineering Tribology 216.4 (2002): 229-248.

[21] Kurbet, S. N., and Kumar. R. K., "A finite element study of piston tilt effects on piston ring dynamics in internal combustion engines", Proceedings of the Institution of Mechanical Engineers, Part K: Journal of Multi-body Dynamics, 218.2 (2004): 107-117.

[22] Baelden, C. and Tian, T., "A Dual Grid Curved Beam Finite Element Model of Piston Rings for Improved Contact Capabilities" SAE International Journal of Engines, 7(1) (2014): 156-171

[23] Ma, M. T., E. H. Smith, and Sherrington, I, "Analysis of lubrication and friction for a complete piston-ring pack with an improved oil availability model: Part 2: Circumferentially variable film." Proceedings of the Institution of Mechanical Engineers, Part J: Journal of Engineering Tribology 211.1 (1997): 17-27.

[24] Baker, C. E., Theodossiades, S., Rahnejat, H., and Fitzsimons, B., "Influence of In-Plane Dynamics of Thin Compression Rings on Friction in Internal Combustion Engines", ASME J Gas Turb Pwr, 2012, 134: 092801.

[25] Baker, C.E., Rahmani, R., Theodossiades, S., Rahnejat, H. and Fitzsimons, B., "On the Effect of Transient In-plane Dynamics of the Compression Ring upon its Tribological Performance", ASME J Gas Turb Pwr, 2015, 137(3), 032512.

[26] Takiguchi, M., Sasaki, R., Takahashi, I., Ishibashi, F., Furuhama, S., Kai, R., and Sato, M., "Oil film thickness measurement and analysis of a three ring pack in an operating diesel engine." SAE paper (2000): 01-1787.

[27] Lang, T. E., "Vibration of thin circular rings", Jet Propulsion Laboratory Technical Report 32-261 (1962). 
[28] Ojalvo, I. U., "Coupled twist-bending vibrations of incomplete elastic rings", International Journal of Mechanical Sciences 4.1 (1962): 53-72.

[29] Burington, R. S., "Handbook of Mathematical Tables and Formulas", 3rd Ed., Handbook Publishers, Ohio, (1958)

[30] Archer, R. R., "Small vibrations of thin incomplete circular rings", International Journal of Mechanical Sciences 1.1 (1960): 45-56.

[31] Morris, N., Rahmani, R., Rahnejat, H., King, P.D. and Fitzsimons,B., "Tribology of piston compression ring conjunction under transient thermal mixed regime of lubrication", Tribology International, 2013, 59: 248-258.

[32] Dowson, D. and Higginson, G.R., "A numerical solution to the elastohydrodynamic problem", Journal of Mechanical Engineering Science, 10.1 (1959): 6-15

[33] Houpert L., "New results of traction force calculations in elastohydrodynamic contacts", ASME Journal of Tribology, 107 (1985): 241-248

[34] Greenwood, J. A., and J. H. Tripp. "The contact of two nominally flat rough surfaces." Proceedings of the Institution of Mechanical Engineers 185.1 (1970): 625-633.

[35] Teodorescu, M., Balakrishnan, S. and Rahnejat, H., "Integrated tribological analysis within a multi-physics approach to system dynamics." Tribology and Interface Engineering Series 48, 2005, pp. 725-737.

[36] Styles, G., Rahmani, R., Rahnejat, H. and Fitzsimons, B., "In-cycle and life-time friction transience in piston ring-liner conjunction under mixed regime of lubrication", International Journal of Engine research, 2014, 15(7): 862-876.

[37]- Baker, C., Rahmani, R., Karagiannis, I., Theodossiades, S., Rahnejat, R. and Frendt, A. "Effect of Compression Ring Elastodynamics Behaviour upon Blowby and Power Loss", SAE Technical Paper, No. 2014-01-1669, 2014 